\title{
The Importance of Ocean Dynamical Feedback for Understanding the Impact of Mid-High-Latitude Warming on Tropical Precipitation Change ${ }^{\mathscr{D}}$
}

\author{
MASAKAZU YOSHIMORI \\ Faculty of Environmental Earth Science, Global Institution for Collaborative Research and Education, and \\ Arctic Research Center, Hokkaido University, Sapporo, Japan
}

AYAKO ABE-OUCHI

Atmosphere and Ocean Research Institute, The University of Tokyo, Kashiwa, and Japan Agency for Marine-Earth Science and Technology, Yokohama, and National Institute of Polar Research, Tachikawa, Japan

HIROAKI TATEBE

Japan Agency for Marine-Earth Science and Technology, Yokohama, Japan

TORU NOZAWA

Okayama University, Okayama, Japan

AKIRA OKA

Atmosphere and Ocean Research Institute, The University of Tokyo, Kashiwa, Japan

(Manuscript received 12 June 2017, in final form 15 December 2017)

\begin{abstract}
It has been shown that asymmetric warming between the Northern and Southern Hemisphere extratropics induces a meridional displacement of tropical precipitation. This shift is believed to be due to the extra energy transported from the differentially heated hemisphere through changes in the Hadley circulation. Generally, the column-integrated energy flux in the mean meridional overturning circulation follows the direction of the upper, relatively dry branch, and tropical precipitation tends to be intensified in the hemisphere with greater warming. This framework was originally applied to simulations that did not include ocean dynamical feedback, but was recently extended to take the ocean heat transport change into account. In the current study, an atmosphere-ocean general circulation model applied with a regional nudging technique is used to investigate the impact of extratropical warming on tropical precipitation change under realistic future climate projections. It is shown that warming at latitudes poleward of $40^{\circ}$ causes the northward displacement of tropical precipitation from October to January. Warming at latitudes poleward of $60^{\circ}$ alone has a much smaller effect. This change in the tropical precipitation is largely explained by the atmospheric moisture transport caused by changes in the atmospheric circulation. The larger change in ocean heat transport near the equator, relative to the atmosphere, is consistent with the extended energy framework. The current study provides a complementary dynamical framework that highlights the importance of midlatitude atmospheric eddies and equatorial ocean upwelling, where the atmospheric eddy feedback modifies the Hadley circulation resulting in the northward migration of precipitation and the ocean dynamical feedback damps the northward migration from the equator.
\end{abstract}

Supplemental information related to this paper is available at the Journals Online website: https://doi.org/10.1175/JCLI-D-170402.s1.

Corresponding author: Masakazu Yoshimori, myoshimo@ees. hokudai.ac.jp

\section{Introduction}

From paleoclimatic evidence to climate model simulations, it has been reported that the asymmetric warming (or cooling) between the Northern and Southern Hemisphere extratropics induces a meridional displacement of tropical precipitation (Chiang and Friedman 2012). It

DOI: 10.1175/JCLI-D-17-0402.1

(C) 2018 American Meteorological Society. For information regarding reuse of this content and general copyright information, consult the AMS Copyright Policy (www.ametsoc.org/PUBSReuseLicenses). 
was unclear, however, whether the meridional interaction was due to atmospheric or oceanic dynamics, or a combination of both. Starting from a symmetric climate state on either side of the equator, Broccoli et al. (2006) applied asymmetric thermal forcing to the extratropical oceans of an atmospheric general circulation model (AGCM) coupled to a slab (mixed layer) ocean model. They successfully demonstrated that the meridional shift of tropical precipitation can occur primarily through the atmospheric route (without lateral communication in the ocean).

The result of Broccoli et al. (2006) can be understood in terms of the atmospheric energy budget, in which the additional energy added to one hemisphere is transported to the hemisphere with less warming through changes in the Hadley circulation. Generally, the column-integrated energy flux in the mean meridional overturning circulation follows the direction of the upper, relatively dry branch, and tropical precipitation tends to be intensified in the hemisphere with greater warming (or less cooling) (Cvijanovic and Chiang 2013; Kang et al. 2009, 2008; Yoshimori and Broccoli 2008, 2009). This interpretation was termed the "energy flux framework" by Chiang and Friedman (2012), who provided an excellent review of this topic. When an external forcing is applied to the Northern Hemisphere (NH) at mid-high latitudes, the energy balance is not maintained locally at the top of the atmosphere (TOA) and a significant fraction of the extra energy is transported to the Southern Hemisphere ( $\mathrm{SH})$ low latitudes via midlatitude atmospheric eddies and low-latitude Hadley circulation (Bischoff and Schneider 2014; Hwang and Frierson 2013; Kang et al. 2009). The Hadley circulation is an inefficient mechanism for transporting energy meridionally because a substantial part of the dry static energy transport by the upper branch of the Hadley cell is cancelled by the latent heat transport by the lower branch of the Hadley cell. However, as stated by Yoshimori and Broccoli (2009), the Hadley circulation is efficient at exchanging energy at the TOA at low latitudes and hence maintaining the energy balance for the global atmosphere. The energy flux framework was more rigorously considered by Bischoff and Schneider (2014) and Schneider et al. (2014), who also pointed out the importance of net energy input to the tropical atmosphere. The applicability of this extended theory, including a zonally asymmetric component, was demonstrated using the ERA-Interim reanalysis dataset by Adam et al. (2016a) and Adam et al. (2016b).

Recent studies have suggested asymmetric aerosol forcing between the hemispheres as a possible mechanism for the meridional displacement of tropical precipitation during the twentieth century, although this theory is still controversial (Allen et al. 2015; Friedman et al. 2013; Hwang et al. 2013; Rotstayn and Lohmann 2002). As an extension of this theory, it is natural to expect that the energy flux framework can also be applied in climate change studies for the future. Frierson and Hwang (2012) showed that there is a link between the meridional precipitation change in the tropics and changes in the cross-equatorial atmospheric energy transport (AET) caused by an increase in atmospheric $\mathrm{CO}_{2}$. However, none of the studies by Broccoli et al. (2006), Cvijanovic and Chiang (2013), Kang et al. (2008), Kang et al. (2009), Yoshimori and Broccoli (2008), Yoshimori and Broccoli (2009), or Frierson and Hwang (2012) have considered ocean dynamical feedback in their analyses. More recent studies point out the leading role of ocean energy transport (OET) in determining the latitude of the climatological intertropical convergence zone (ITCZ) (Frierson et al. 2013; Fuckar et al. 2013; Marshall et al. 2014). While studies that have taken ocean dynamics into account suggest that variations of the ITCZ latitude on various time scales are still scaled by the cross-equatorial AET (Donohoe et al. 2013; Hwang and Frierson 2013; McGee et al. 2014), Donohoe et al. (2014) and Schneider et al. (2014) argued that the sensitivity of the ITCZ shift to the interhemispheric differential heating would be lowered by the dynamical feedback from the ocean. Deser et al. (2015) examined the response to greenhouse gasinduced Arctic sea ice loss and showed that the meridional shift of tropical precipitation simulated by an AGCM coupled to a thermodynamic-only ocean model is not reproduced by their atmosphere-ocean general circulation model (AOGCM). The simulated response pattern to the Arctic sea ice loss was approximately symmetric with the equator, similar to a full global warming pattern but with a reduced magnitude (Deser et al. 2015, 2016). The role of subtropical meridional ocean cells and OET in suppressing the ITCZ shift was reported by Tomas et al. (2016), Kay et al. (2016), and Hawcroft et al. (2017). Furthermore, Green and Marshall (2017) provided a physical explanation for the response of wind-driven ocean cells in an idealized model experiment. The study by Yim et al. (2017), on the other hand, suggested an intermodel correlation between the future meridional displacement of tropical precipitation and Arctic warming amplification. While rapid progress has been made, our current understanding on the link between extratropical warming and changes in tropical precipitation is still incomplete. The scientific questions that we would like to address in this article are the following: 1) To what extent does the asymmetric extratropical warming between hemispheres explain the change in the distribution of tropical 
precipitation in the future? and 2) What is the dynamical mechanism of the atmosphere and ocean for such a "teleconnection" if it exists?

The rest of this paper is organized as follows. In the next section, a climate model with different levels of atmosphere-ocean interaction is introduced. A series of experiments are described in section 3 . The four distinct analysis methods are explained in section 4. Section 5 presents the results, and the discussions and the conclusions are given in sections 6 and 7, respectively.

\section{Models}

The primary model used in the current study is an AOGCM; the Model for Interdisciplinary Research on Climate (MIROC), version 4 (medium resolution) (MIROC4m). This model is identical to that used in Yoshimori et al. (2014b), and is essentially the same model as the MIROC, version 3.2 (medium resolution) [MIROC3.2(medres); Hasumi and Emori (2004)] used for a suite of experiments archived in phase 3 of the Coupled Model Intercomparison Project (CMIP3; Meehl et al. 2007). The atmosphere and land surface components have a common horizontal resolution of T42 $\left(\sim 2.8^{\circ}\right)$ and the atmosphere has 20 vertical levels. The ocean and sea ice components have a common horizontal resolution of $0.5^{\circ}-1.4^{\circ}$. The ocean has 43 vertical levels with one additional layer for bottom boundary layer parameterization.

The MIROC4m AGCM coupled to a slab ocean component is also used to isolate the effect of ocean dynamical feedback. The slab ocean has a constant depth of $50 \mathrm{~m}$. The model calculates the ocean mixed layer temperature and sea ice distribution, but not the ocean circulation. The effect of OET must be represented by adding predetermined heat fluxes to the mixed layer. This additional heat flux varies with season and location, but is constant between experiments. In this model setting, the land surface, ocean, and sea ice have the same horizontal resolution as the AGCM. The lower boundary conditions for the AGCM [i.e., the sea surface temperature (SST) and sea ice distribution] can also be prescribed globally or regionally as in Yoshimori et al. (2017).

The MIROC4m ocean component (OGCM) is also used with a prescribed surface air temperature, freshwater fluxes, and wind stress to investigate the ocean dynamical response to wind stress changes. Ocean surface heat fluxes are calculated from the prescribed surface air temperature and the simulated SST using a bulk formula as in Oka et al. (2012).

\section{Experiments}

The core experiments conducted in the current study are illustrated in Fig. 1. Starting from the perpetual preindustrial (ca. 1850) control simulation (AO-CTL), AO-RCP4.5 simulations are carried out under historical conditions (1850-2005) and the RCP4.5 forcing scenario (2006-2100) following the CMIP5 protocol (Taylor et al. 2012) except for land-use change (Fig. 1a). Additionally, the RCP2.6 and RCP8.5 scenario simulations are also conducted. The land-use change from AO-CTL is not considered in these time-varying forcing experiments in order to reduce the technical burden of adapting all the CMIP5 forcing datasets for use with the CMIP3 model. We note that the same forcing dataset for MIROC4m was used in the study by Bakker et al. (2016). Three ensemble members are created for the historical and each of the RCP scenario runs. Figure $1 b$ shows the extratropical forcing experiments, AO-R40 and AO$\mathrm{R} 60$, in which the ocean temperature and salinity at higher latitudes than the specified boundaries $\left(40^{\circ}\right.$ or $60^{\circ}$ in both hemispheres) are nudged to those for the simulated historical and RCP4.5 simulations (AO-RCP4.5) with a restoring time scale of 10 days. We note that this restoring technique was used previously by Tatebe et al. (2013). In AO-R40 and AO-R60, there is no radiative forcing relative to $\mathrm{AO}-\mathrm{CTL}$, and the ocean temperature and salinity at lower latitudes than the boundaries (i.e., $40^{\circ}$ or $60^{\circ}$ ) respond freely to the prescribed higherlatitude changes. While the nudging technique is useful to reproduce the partial response of the full model configuration, it does not conserve the total energy for the entire domain of the model. The AO-R40 and AOR60 experiments aim to remove the direct tropical response to the radiative forcing from AO-RCP4.5 and extract only the remote influence of extratropical warming on the tropics. The AO-RS40 experiment illustrated in Fig. 1c is identical to AO-R40 except that the restoration of temperature and salinity is applied only to the top surface level of the ocean. The AORW40 experiment illustrated in Fig. 1d is identical to AO-R40 except that the ocean temperature and salinity at the grid points neighboring the $40^{\circ}$ boundaries are restored to those for AO-CTL. In comparison to AO$\mathrm{R} 40$, the AO-RS40 experiment is expected to reveal the sensitivity to the internal ocean perturbation, and AORW40 is intended to remove the direct oceanic pathways connecting the extratropical influence to the tropics. Three ensemble members covering 1850 to 2100 are created for each of the AO-R40, AO-R60, AORS40, and AO-RW40 experiments, and the ensemble mean is calculated.

In addition to the AOGCM experiments, AGCM experiments coupled to a slab ocean model (AS-R40a and AS-R40b) or under fixed SST and sea ice conditions (A-R40a and A-R40b) are carried out. In AS-R40a and AS-R40b, illustrated in Figs. 1e and 1f, respectively, a 

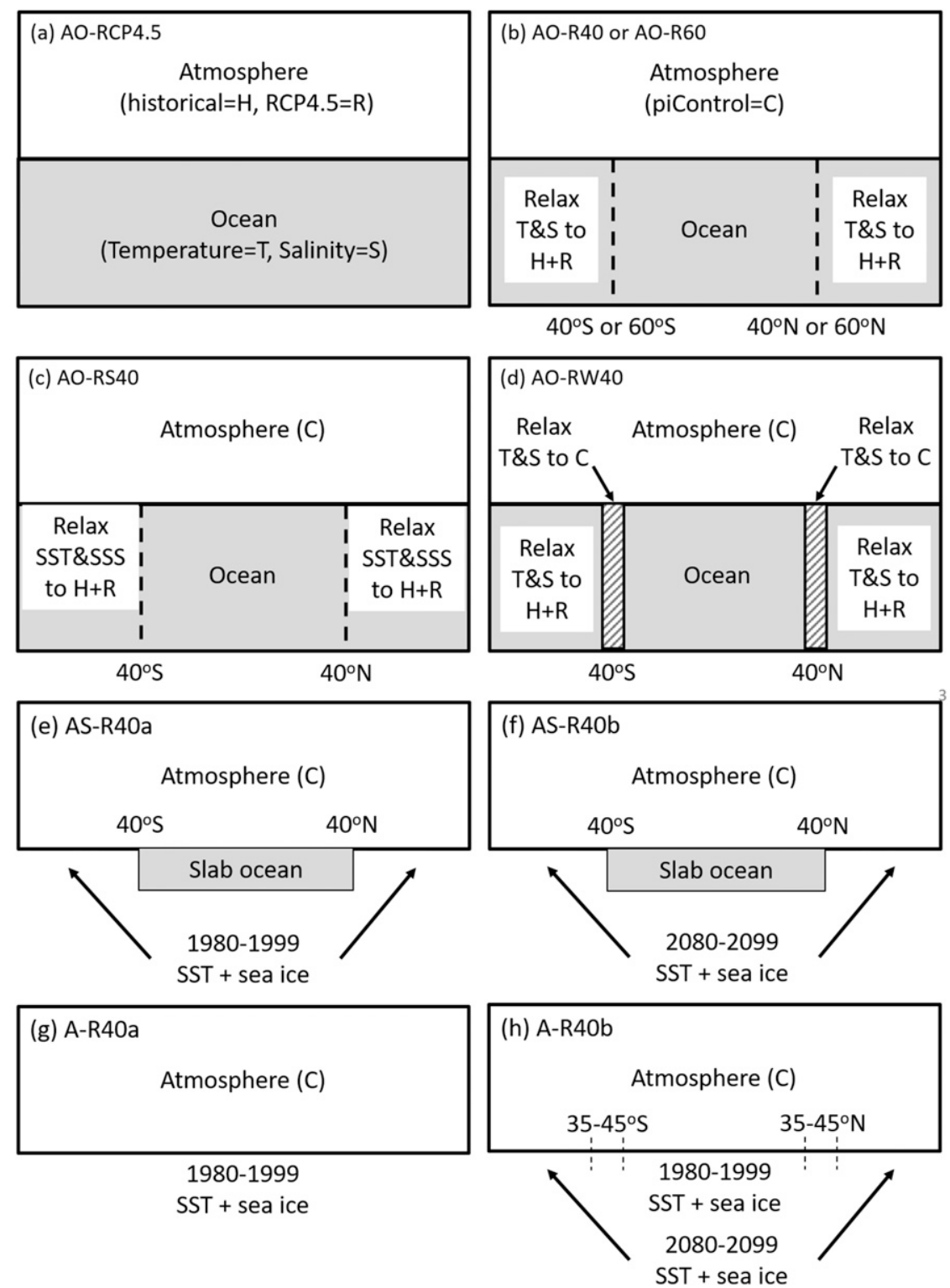

FIG. 1. (a)-(h) Illustration of the experiments. "C," "H," and "R" stand for preindustrial control (piControl), historical, and RCP-scenario simulations, respectively. "T" and "S" stand for ocean temperature and salinity, respectively. "SST" and "SSS" stand for sea surface temperature and sea surface salinity, respectively. "1980-1999" and "2080-2099" are the 20-yr averages of these periods. "Relax" means that the variable is restored to the archived data with the time scale of 10 days. In (h), linear interpolation is applied over $35^{\circ}-45^{\circ}$. See the text for the details of each experiment.

slab ocean is used as the lower boundary of the AGCM except for the SST and sea ice distribution at $40^{\circ}-90^{\circ} \mathrm{S}$ and $40^{\circ}-90^{\circ} \mathrm{N}$, which are prescribed as the $1980-99$ average (AS-R40a) or 2080-99 average (AS-R40b), taken from AO-RCP4.5. While the SST (or mixed layer ocean temperature) between $40^{\circ} \mathrm{S}$ and $40^{\circ} \mathrm{N}$ can freely respond to the extratropical warming conditions in AS-R40a and AS-R40b, the SST between $35^{\circ} \mathrm{S}$ and $35^{\circ} \mathrm{N}$ is also prescribed as the 1980-99 conditions in A-R40a and AR40b (Figs. $1 \mathrm{~g}$ and $1 \mathrm{~h}$ ). The 1980-99 conditions are also prescribed for $35^{\circ}-90^{\circ} \mathrm{S}$ and $35^{\circ}-90^{\circ} \mathrm{N}$ in A-R $40 \mathrm{a}$. In A$\mathrm{R} 40 \mathrm{~b}$, the $2080-99$ conditions are used for $45^{\circ}-90^{\circ} \mathrm{S}$ and $45^{\circ}-90^{\circ} \mathrm{N}$, and the lower boundary conditions for the transition latitudes of $35^{\circ}-45^{\circ} \mathrm{N} / \mathrm{S}$ are smoothed by linearly interpolating sea surface conditions from 1980-99 to 2080-99. The difference between AS-R40a and 
TABLE 1. List of OGCM experiments.

\begin{tabular}{lllr}
\hline \multicolumn{1}{c}{ Expt } & \multicolumn{1}{c}{ Wind stress anomaly } & \multicolumn{1}{c}{ Initial conditions } & Integration length (analysis period) \\
\hline O-CTL & & Arbitrary & $2050 \mathrm{yr}(\mathrm{last} 40 \mathrm{yr})$ \\
O-AOR40 & (2080-99 avg) $-(1980-99 \mathrm{avg})$ in AO-R40 & The year 2001 in O-CTL & $50 \mathrm{yr}$ (last $40 \mathrm{yr})$ \\
O-ASR40 & AS-R40b - AS-R40a & The year 2001 in O-CTL & $50 \mathrm{yr}$ (last 40 yr) \\
\hline
\end{tabular}

AS-R40b (AS-R40b - AS-R40a, hereafter, AS-R40) aims to isolate the remote influence of mid-high-latitude warming via atmospheric and ocean-thermodynamic feedbacks, while the difference between A-R40a and A-R $40 \mathrm{~b}$ aims to further exclude the thermal response of the ocean. The model is integrated over 60 years, and the last 30 years are used for the analysis in AS-R40a and AS-R40b. The model is also integrated for 40 years, and the last 30 years are used for the analysis in A-R40a and A-R40b.

The OGCM experiments are listed in Table 1. We use the preindustrial control simulation of Oka et al. (2012) as the reference state (O-CTL), in which the upper boundary conditions for the OGCM are taken from the AOGCM preindustrial simulation (with CMIP3 forcings) of the same model. The model is integrated for 2050 years to quasi equilibrium. The first sensitivity experiment, O-AOR40, applies the wind stress anomaly of the difference between 1980-99 and 2080-99 in the coupled AOGCM experiment, AO-R40. The second sensitivity experiment, O-ASR40, applies the wind stress anomaly of the AS-R40 slab ocean AGCM experiments. In both O-AOR40 and O-ASR40, the model is integrated for 50 years and the last 40 years are compared with the last 40 years of O-CTL. The results represent the upper-ocean response to the wind stress anomaly on multidecadal time scales.

\section{Analysis method}

\section{a. Horizontal convergence of moisture flux}

The factors contributing to the change in the horizontal distribution of precipitation-minus-evaporation $(P-E)$ are analyzed using the same approach as in Yoshimori et al. (2006). The moisture budget for each atmospheric column is given by

$$
\frac{\partial\langle q\rangle}{\partial t}=-\nabla_{H} \cdot\langle\mathbf{V} q\rangle+E-P,
$$

where $q$ and $t$ are the specific humidity and time, respectively; and $E$ and $P$ are the evaporation and precipitation at the surface, respectively. The term $\mathbf{V}$ is the horizontal velocity vector, and $\nabla_{H}$ denotes the horizontal divergence operator. The angle brackets denote the vertical integral, that is,

$$
\langle\phi\rangle \equiv-\frac{1}{g} \int_{p_{S}}^{0} \phi d p
$$

for an arbitrary variable $\phi$. Here $g$ is the gravitational acceleration. To measure the difference between two climate states (the late twenty-first century minus the late twentieth century in the current study, denoted by $\Delta$ ), Eq. (1) becomes

$$
\Delta(\bar{P}-\bar{E})=-\nabla_{H} \cdot\langle\Delta \overline{\mathbf{V} q}\rangle+\varepsilon .
$$

Here, $\varepsilon$ represents the (small) change in the amount of water vapor in the atmosphere. At low latitudes, the effect of transient eddies on moisture transport is small, and thus the following decomposition can be obtained using the monthly mean field (denoted by the overbar):

$$
\Delta \overline{\mathbf{V} q}=\bar{q}_{0} \Delta \overline{\mathbf{V}}+\overline{\mathbf{V}}_{0} \Delta \bar{q}+\Delta \overline{\mathbf{V}} \Delta \bar{q}+\varepsilon^{\prime},
$$

where we use the average of the two climate states for the variable with subscript " 0 ." The first, second, third, and fourth terms on the right-hand side of Eq. (4) represent the effect of changes in the monthly mean climatologies of the wind, specific humidity, the combined effect of both changes, and the residual, respectively. The analysis is conducted using monthly data at 18 pressure levels, and it is confirmed that the synergy, $\varepsilon$, and $\varepsilon^{\prime}$ terms are all small in the tropics.

\section{b. Meridional convergence of moisture flux}

The factors contributing to the change in the meridional convergence of the moisture flux are analyzed to quantify how much of the meridional displacement of the change in the precipitation is attributable to changes in the Hadley circulation. The zonally averaged moisture budget in the atmosphere is given by

$$
\left[\frac{\partial\langle q\rangle}{\partial t}\right]=-\frac{1}{a \cos \varphi} \frac{\partial}{\partial \varphi}\langle[v q] \cos \varphi\rangle+[E-P],
$$

where $\varphi$ and $a$ are the latitude and radius of Earth, respectively; and the square brackets denote the zonal average. When ignoring the change in the amount of atmospheric water vapor, Eq. (5) becomes

$$
\Delta[\bar{P}-\bar{E}]=-\frac{1}{a \cos \varphi} \frac{\partial}{\partial \varphi}\langle\Delta[\overline{v q}] \cos \varphi\rangle .
$$


The inside of the angle brackets in Eq. (6) can be decomposed as follows:

$$
\Delta[\overline{v q}]=\Delta([\bar{q}][\bar{v}])+\Delta\left[\bar{q}^{*}\right]\left[\bar{v}^{*}\right]+\Delta\left[\overline{q^{\prime} v^{\prime}}\right],
$$

where the star and dash represent departures from the zonal mean and the monthly mean, respectively. The first, second, and third terms on the right-hand side of Eq. (7) represent the contributions of the mean circulation, stationary eddies, and transient eddies, respectively. The mean circulation term is further decomposed into the effect of the zonal mean specific humidity, zonal mean meridional velocity (i.e., the Hadley circulation), and synergy terms:

$$
\Delta([\bar{q}][\bar{v}])=[\bar{v}] \Delta[\bar{q}]+[\bar{q}] \Delta[\bar{v}]+\Delta[\bar{q}] \Delta[\bar{v}] .
$$

The analysis is made on the native model vertical (sigma) levels using the formula provided by Keith (1995), which takes the time variation of the layer thickness into account.

\section{c. Atmospheric meridional streamfunction}

The factors contributing to changes in the Hadley circulation are analyzed. Based on the zonal mean continuity equation, the atmospheric meridional streamfunction $\psi$ can be defined to satisfy

$$
([v],[\omega])=\frac{g}{2 \pi a \cos \varphi}\left(\frac{\partial \psi}{\partial p},-\frac{1}{a} \frac{\partial \psi}{\partial \varphi}\right),
$$

where $p$ and $\omega$ are the pressure and vertical pressure velocity, respectively. The factors contributing to the meridional streamfunction are analyzed by solving the Kuo-Eliassen equation. The Kuo-Eliassen equation is derived by substituting the zonal mean zonal momentum and thermodynamic equations into the thermal wind balance equation. Following the derivation by Krishnamurti et al. (2013, 10-13), we have

$$
\begin{aligned}
& A \frac{\partial^{2} \psi}{\partial p^{2}}+\frac{2 B}{a} \frac{\partial^{2} \psi}{\partial \varphi \partial p}+\frac{C}{a^{2}} \frac{\partial^{2} \psi}{\partial \varphi^{2}}+2 B \frac{\tan \varphi}{a} \frac{\partial \psi}{\partial p}+C \frac{\tan \varphi}{a^{2}} \frac{\partial \psi}{\partial \varphi} \\
& \quad=\frac{2 \pi a \cos \varphi}{g}\left(\frac{\partial M}{\partial p}-\frac{R \Pi}{p f} \frac{1}{a} \frac{\partial H}{\partial \varphi}\right),
\end{aligned}
$$

where

$$
\begin{gathered}
A \equiv-f+\frac{1}{a} \frac{\partial[u]}{\partial \varphi}-\frac{\tan \varphi}{a}[u], B \equiv-\frac{\partial[u]}{\partial p}, C \equiv \frac{R \Pi}{p f} \frac{\partial[\theta]}{\partial p} \\
\bar{M} \equiv-\frac{1}{a \cos ^{2} \varphi} \frac{\partial}{\partial \varphi}\left(\left[\bar{u}^{*} \bar{\tau}^{*}\right] \cos ^{2} \varphi\right)-\frac{\partial}{\partial p}\left[\bar{u}^{*} \bar{\omega}^{*}\right] \\
-\frac{1}{a \cos ^{2} \varphi} \frac{\partial}{\partial \varphi}\left(\left[\overline{u^{\prime} v^{\prime}}\right] \cos ^{2} \varphi\right)-\frac{\partial}{\partial p}\left[\overline{u^{\prime} \omega^{\prime}}\right]+[\bar{F}],
\end{gathered}
$$

$$
\begin{aligned}
\bar{H} \equiv & -\frac{1}{a \cos \varphi} \frac{\partial}{\partial \varphi}\left(\left[\bar{v}^{*} \bar{\theta}^{*}\right] \cos ^{2} \varphi\right)-\frac{\partial}{\partial p}\left[\bar{\omega}^{*} \bar{\theta}^{*}\right] \\
& -\frac{1}{a \cos \varphi} \frac{\partial}{\partial \varphi}\left(\left[\overline{v^{\prime} \theta^{\prime}}\right] \cos ^{2} \varphi\right)-\frac{\partial}{\partial p}\left[\overline{\omega^{\prime} \theta^{\prime}}\right]+\frac{[\bar{Q}]}{\Pi}, \\
\Pi= & \left(\frac{p}{p_{0}}\right)^{\kappa} .
\end{aligned}
$$

Here, $f$ is the Coriolis parameter, $F$ is the zonal friction, $Q$ is the diabatic heating rate, $p_{0}$ is the reference pressure $(1000 \mathrm{hPa})$, and $\kappa$ is the ratio of the gas constant and specific heat for air. While the above equation is not widely known by this name, essentially the same diagnostic equation appears in standard textbooks (e.g., Grotjahn 1993, 249-264; Holton and Hakim 2013, 330337). The analysis is conducted using daily data for 18 pressure levels and the equation is numerically solved for each month using the successive overrelaxation method (e.g., Press et al. 1992, 857-860). We note that zonal mean missing values below the surface pressure levels are filled by the existing zonal mean values at the level above to compute the derivatives.

\section{d. Climate feedback-response analysis method}

The factors contributing to changes in the surface temperature are analyzed using the climate feedbackresponse analysis method (CFRAM), originally developed by Lu and Cai (2009). This method is based on the energy balance equations for the atmosphere and the surface, and the equations are simultaneously solved for the temperature changes at atmospheric levels and the surface for each atmospheric column for each month. For the difference between the two climate states, the energy balance equations yield

$$
\Delta T_{k}=\left(\frac{\partial R_{j}}{\partial T_{k}}\right)^{-1} \Delta E_{j},
$$

where $T$ and $E$ are the temperature and energy flux convergence at $N$ atmospheric levels and the surface $(j=1,2, \ldots, N, N+1 ; k=1,2, \ldots, N, N+1)$. The divergence of longwave radiative fluxes per unit temperature perturbation at each level, $\left(\partial R_{j} / \partial T_{k}\right)$, is precomputed by using the radiative transfer part of the same AGCM for each grid point for each month.

The application of CFRAM to the MIROC models has been described in detail in previous publications (Yoshimori et al. 2017, 2014a,b), and thus is only briefly explained here. We use the same procedure as Yoshimori et al. (2017). The temperature change due to individual processes is diagnosed separately by estimating $\Delta \mathbf{E}$ for each process. The resulting temperature change is called the partial temperature change. The 
validity of the analysis is evaluated by checking if the sum of individual partial temperature changes explains the simulated temperature change:

$$
\begin{aligned}
\Delta \mathbf{T}= & \Delta \mathbf{T}^{\mathrm{EXT}}+\Delta \mathbf{T}^{\mathrm{WVP}}+\Delta \mathbf{T}^{\mathrm{ALB}}+\Delta \mathbf{T}^{\mathrm{CLD}}+\Delta \mathbf{T}^{\mathrm{ERR}} \\
& +\Delta \mathbf{T}^{\mathrm{EVP}}+\Delta \mathbf{T}^{\mathrm{SH}}+\Delta \mathbf{T}^{\mathrm{LSC}}+\Delta \mathbf{T}^{\mathrm{CUM}}+\Delta \mathbf{T}^{\mathrm{VDF}} \\
& +\Delta \mathbf{T}^{\mathrm{DYN}}+\Delta \mathbf{T}^{\mathrm{RESA}}+\Delta \mathbf{T}^{\mathrm{RESS}}
\end{aligned}
$$

where the superscripts EXT, WVP, ALB, CLD, and ERR denote the radiative components due to external forcing, water vapor feedback, surface albedo feedback, cloud feedback, and small terms arising from the shortwave nonlinear effect of albedo and cloud changes, respectively. The superscripts EVP, SH, LSC, CUM, VDF, and DYN denote the nonradiative components due to surface evaporation, sensible heat flux, largescale condensation, cumulus convection, vertical diffusion, and atmospheric advection, respectively. The RESS term represents the net surface heat flux including the effect of ocean heat storage, oceanic advection, and the melting of snow and ice (at high latitudes), while RESA is the atmospheric heat storage. The readers are referred to Yoshimori et al. (2017) for further details.

\section{Results}

\section{a. Temperature and precipitation response}

In this section, we primarily discuss results of AORCP4.5, AO-R40, and AO-R60. A brief overview of the historical and RCP simulations is given in the supplemental materis (see Fig. S1). In the following, we present the results for the late twentieth century (1980-99 average), the late twenty-first century (2080-99 average), and the difference between them (the late twenty-first century - the late twentieth century). The robustness of the difference is assessed based on whether the sign of the change is consistent for the three ensemble members of the transient AOGCM experiments, and a two-sided $t$ test for the AGCM-slab ocean model and OGCM experiments under constant forcing. Only the robust results are discussed below, and robustness is indicated by stippling in the figures unless the clarity is compromised.

Although the sea ice distribution and land surface temperature are not restored in AO-R40 and AO-R60, they reproduce the surface air temperature in the $\mathrm{AO}$ RCP4.5 mid-high-latitude warming well (Fig. S2). As expected, warming at lower latitudes is smaller in AO$\mathrm{R} 40$ and in AO-R60, compared to AO-RCP4.5. In addition, the seasonal evolution of the $\mathrm{NH}$ sea ice area (Fig. 2a) and the minimum of the September sea ice
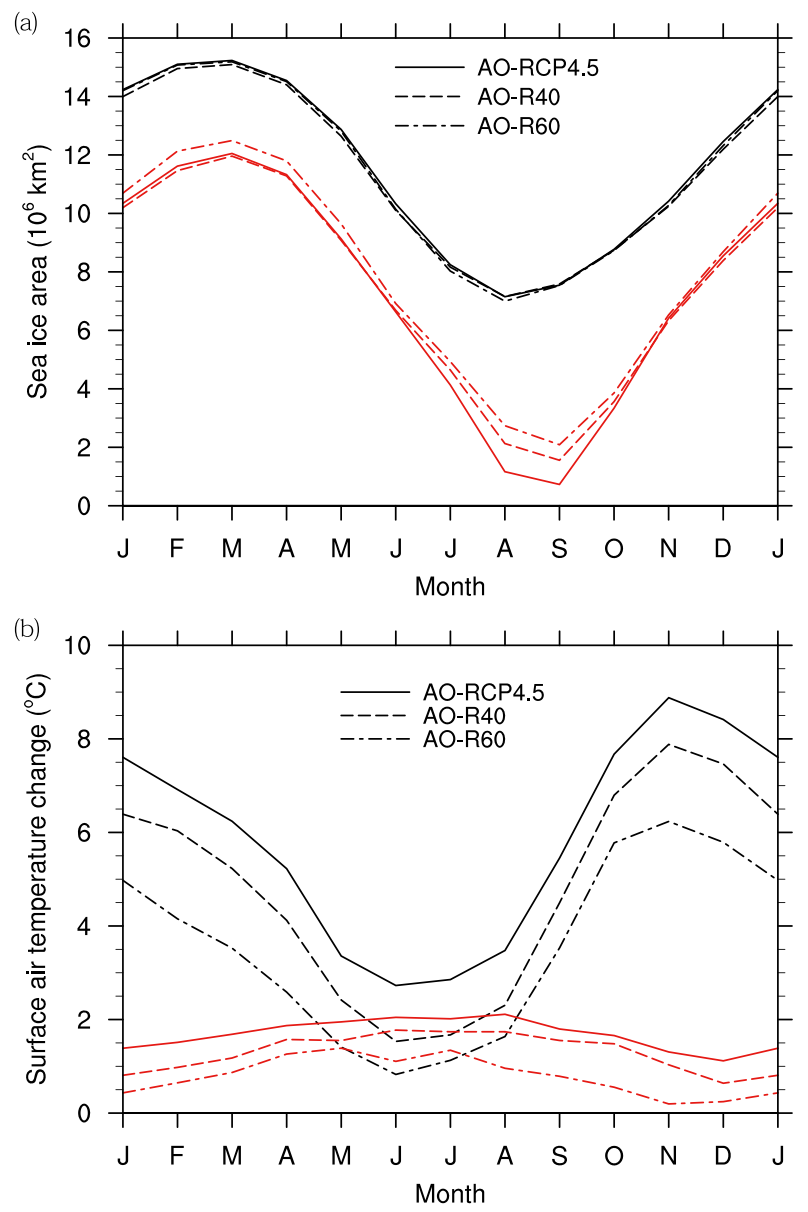

FIG. 2. Annual cycle: (a) Northern Hemisphere sea ice area $\left(\times 10^{6} \mathrm{~km}^{2}\right)$. Black lines represent the late twentieth century, while the red lines represent the late twenty-first century. (b) Surface air temperature changes from the late twentieth century to the late twenty-first century at high latitudes $\left({ }^{\circ} \mathrm{C}\right)$. The black lines represent the average for $60^{\circ}-90^{\circ} \mathrm{N}$, while the red lines represent the average for $60^{\circ}-90^{\circ} \mathrm{S}$. In both (a) and (b), the solid, dashed, and dot-dashed lines (in both black and red colors) represent AO-RCP4.5, AO-R40, and AO-R60, respectively.

distribution (not shown) in AO-R40 and AO-R60 resemble those for AO-RCP4.5. Figure $2 \mathrm{~b}$ shows the seasonal evolution of the surface air temperature at high latitudes. There is little seasonality in the SH temperature response and the largest contrast in the response of the $\mathrm{NH}$ and $\mathrm{SH}$ temperature is seen from autumn to winter in all three experiments, consistent with many previous studies (e.g., Deser et al. 2010; Laîné et al. 2016; Yoshimori et al. 2014b). The smaller response of AO-R40 and AO-R60 in mid-high latitudes, compared to AO$\mathrm{RCP} 4.5$, is due to the lack of radiative forcing and consequent lower land surface warming. We conclude that the AO-R40 and AO-R60 experiments are useful in our analysis as they isolate the extratropical warming influence on the tropics from the AO-RCP4.5 simulation. 
Figures $3 \mathrm{a}-\mathrm{c}$ show the October-January average precipitation changes in AO-RCP4.5, AO-R40, and AOR60. Hereafter, we focus on this season because the meridional displacement of tropical precipitation is most pronounced in this season for AO-RCP4.5 (Fig. S3). This is also the season when the greatest warming occurs in the Arctic (Fig. 2b). In AO-RCP4.5, there is a striking decrease and increase in the precipitation in the South $\mathrm{Pa}-$ cific convergence zone (SPCZ) and NH tropical Pacific, respectively. A substantial fraction of this meridional shift is captured by AO-R40 in which only the extratropical warming conditions were imposed. As much as $47 \%$ of the tropical precipitation changes between north and south of $10^{\circ} \mathrm{S}$ in AO-RCP4.5 are also seen in AO-R40 (Table 2). High-latitude warming in AO-R60 exhibits little relation with the tropical precipitation, however. We discuss the sensitivity of the response to the forcing at different latitudes in section 6, but focus on AO-R40 for the rest of current section.

To identify the cause of the tropical precipitation change, we decomposed the $P-E$ change into the humidity and circulation components following the method described in section 4a. As the change in the evaporation is relatively small, the $P-E$ change (Fig. 4a) resembles the precipitation change (Fig. 3b). In addition, the moisture flux convergence change, diagnosed by the monthly mean specific humidity and wind velocity, reproduces the $P-E$ change in the tropics well where eddy activities are small (Fig. 4b). Figure $4 \mathrm{c}$ indicates that the effect of circulation change dominates the $P-E$ response (the humidity effect is small and the synergy term for the humidity and circulation changes is even smaller; not shown). To relate the $P-E$ change to the Hadley circulation, we conducted a similar decomposition of factors for the zonal mean $P-E$ change following the method described in section 4b. As the $P-E$ change in the tropics is mostly explained by the moisture convergence due to variations in the mean meridional circulation (MMC), rather than by stationary or transient eddies, we only present the results for the MMC terms in Fig. 5. In both AO-RCP4.5 and AO-R40, the dominant term for the dipole pattern of the moisture flux convergence change (and thus the $P-E$ change) is the circulation term (i.e., the Hadley circulation). The humidity term contributes substantially to the increase in the equatorial convergence but much less to the northward shift from the southern tropics compared to the circulation term. This result is consistent with the idea proposed by Hill et al. (2015) that the dynamical response dominates the thermodynamic response at the deep tropical latitudes where the difference from the ITCZ in surface temperature anomaly is small. (a)

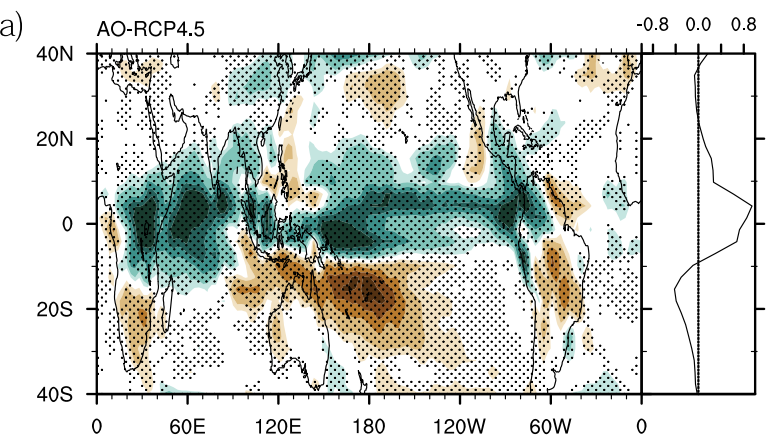

(b)

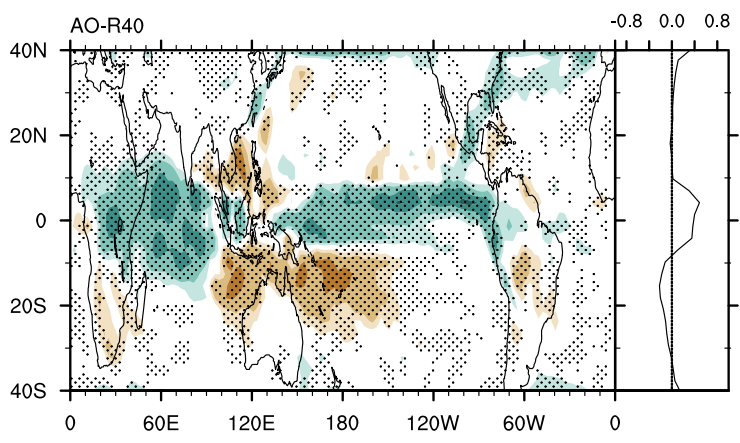

(c)

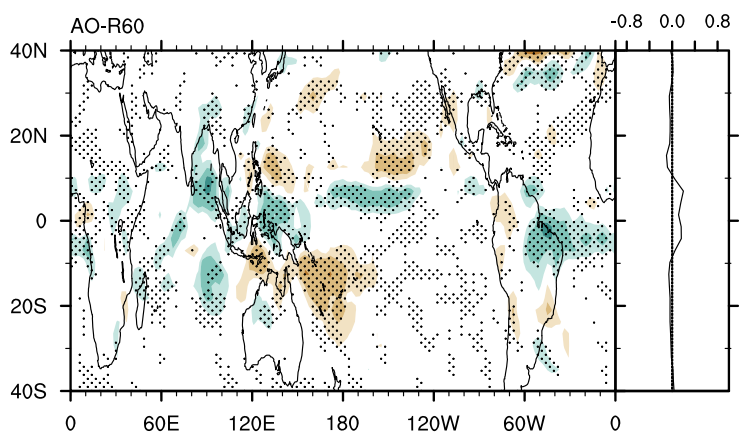

(d)

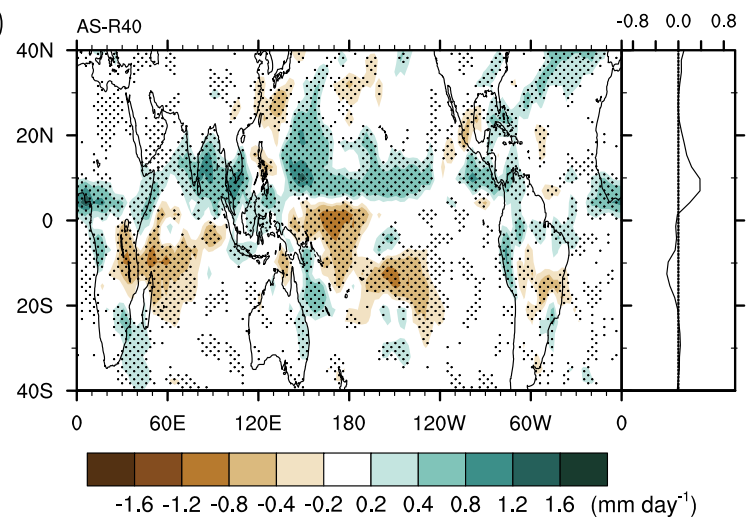

FIG. 3. Precipitation changes (October-January, $\mathrm{mm} \mathrm{day}^{-1}$ ): (a) AO-RCP4.5, (b) AO-R40, (c) AO-R60, and (d) AS-R40b AS-R40a. Zonal means are shown on the right. In (a)-(c), the grid points where the three ensemble members exhibit the same sign for the anomaly are stippled. In (d), the grids points where the difference is significant at the $5 \%$ level according to a $t$ test are stippled. 
TABLE 2. Tropical precipitation change from the late twentieth century to the late twenty-first century (October-January). The bottom row is the difference between AS-R $40 \mathrm{~b}$ and AS-R $40 \mathrm{a}$, and $20^{\circ} \mathrm{S}-0^{\circ}, 0^{\circ}-20^{\circ} \mathrm{N}$ averages are used instead of $30^{\circ}-10^{\circ} \mathrm{S}, 10^{\circ} \mathrm{S}-10^{\circ} \mathrm{N}$ averages. $(\mathrm{d})$ The percentage to AO-RCP4.5 in (c) is shown.

\begin{tabular}{|c|c|c|c|c|}
\hline Expt & $\begin{array}{c}\text { (a) } 30^{\circ}-10^{\circ} \mathrm{S}\left(\text { or } 20^{\circ} \mathrm{S}-0^{\circ}\right) \\
\left(\mathrm{mm} \mathrm{day}^{-1}\right)\end{array}$ & 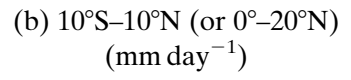 & (c) (b) - (a) $\left(\mathrm{mm} \mathrm{day}^{-1}\right)$ & (d) Fraction (\%) \\
\hline AO-RCP4.5 & -0.28 & 0.54 & 0.82 & 100 \\
\hline AO-R40 & -0.15 & 0.24 & 0.39 & 47 \\
\hline AO-R60 & -0.04 & 0.11 & 0.14 & 18 \\
\hline AO-RS40 & -0.04 & 0.12 & 0.17 & 20 \\
\hline AO-RW40 & -0.11 & 0.15 & 0.26 & 32 \\
\hline AS-R40b - AS-R40a & -0.10 & 0.20 & 0.31 & NA \\
\hline
\end{tabular}

\section{b. Change in mean meridional circulation of the atmosphere}

Figure 6 shows the atmospheric meridional streamfunction between $60^{\circ} \mathrm{S}$ and $60^{\circ} \mathrm{N}$. The line contours show the streamfunction in the late twentieth century and the color shadings show the change from the late twentieth to the late twenty-first centuries. Throughout the paper, we use the terms "clockwise" and "counterclockwise" looking at the North Pole on the right side. In both AORCP4.5 and AO-R40, there are counterclockwise Hadley circulation anomalies that overlap with the boundaries of the northern and southern Hadley cells in the late twentieth century (Figs. 6a and 6b). This counterclockwise anomaly is consistent with the transport of moisture from the $\mathrm{SH}$ to the $\mathrm{NH}$ by the lower branch of the Hadley cell, causing the northward shift in the precipitation distribution.

The contributions of different processes to the anomalous Hadley circulation are diagnosed by solving the Kuo-Eliassen equation described in section 4c. As the Kuo-Eliassen equation is a diagnostic equation, it does not provide information on the sequential causality. It does, however, reveal which components among the meridional differential heating due to the diabatic effect, (stationary and transient) eddy momentum fluxes, eddy heat fluxes, and frictional drag are important to maintain the simulated Eulerian mean meridional circulation, given the distribution of zonal mean zonal wind and potential temperature. Such a decomposition helps to identify which processes amplify or suppress the response. Here, we focus our analysis on the AO-R40 experiment. The sum of all the individual terms reproduces the Hadley circulation anomaly well (Fig. 6c), indicating that the decomposition of the streamfunction into its individual contributions is useful. Note that small errors are expected due to the numerical discretization and the use of pressure coordinates in addition to the assumption of thermal wind balance. Figure 7 shows the contribution from the four sources between $60^{\circ} \mathrm{S}$ and $60^{\circ} \mathrm{N}$ : northward (stationary and transient) eddy momentum flux, eddy heat flux, diabatic heating, and friction. The diabatic heating and eddy terms are important in the $\mathrm{SH}$ and $\mathrm{NH}$ tropics, respectively, in transporting moisture northward. The contributions of the vertical eddy momentum and heat fluxes are very small and not shown here. The reduced northward eddy momentum fluxes at the subtropical to midlatitudes induce a convergence of the angular momentum in the upper troposphere at low latitudes (Fig. 8a). In the steady state, this convergence is balanced by the Coriolis force accompanying a southward flow (Fig. 7a). Similarly, the reduced northward eddy heat transport at the subtropical to midlatitudes induces a convergence of the heat fluxes at low latitudes (Fig. 8b). In the steady state, the heating due to this convergence is balanced by the adiabatic cooling, which accompanies the upward motion around $30^{\circ} \mathrm{N}$ (Fig. 7b). Therefore, the reduction in the northward eddy transport of momentum and heat drives the anomalous counterclockwise northern Hadley cell. We note that comparable contributions are made by stationary and transient eddies to the transport of both heat and momentum. The frictional drag against the easterly deceleration is balanced by the Coriolis force accompanying a northward flow near the surface (Fig. 7d). The anomalous counterclockwise Hadley cell in the $\mathrm{NH}$ tropics is partially cancelled by the anomalous clockwise Hadley cell because of differential diabatic heating near the equator (Fig. 7c), although the net response is still counterclockwise in the NH tropics (Fig. 6c). The large diabatic heating with upward motion near the equator creates the counterclockwise and clockwise Hadley cell anomalies in the SH and NH tropics, respectively (Fig. 8c).

\section{c. Sea surface temperature response}

The large diabatic heating in the equatorial region is attributed to the maximum of the SST anomaly in the eastern equatorial Pacific (Figs. 9a and 9b). The surface wind anomaly converges at this peak SST warming in both AO-RCP4.5 and AO-R40. To identify which 

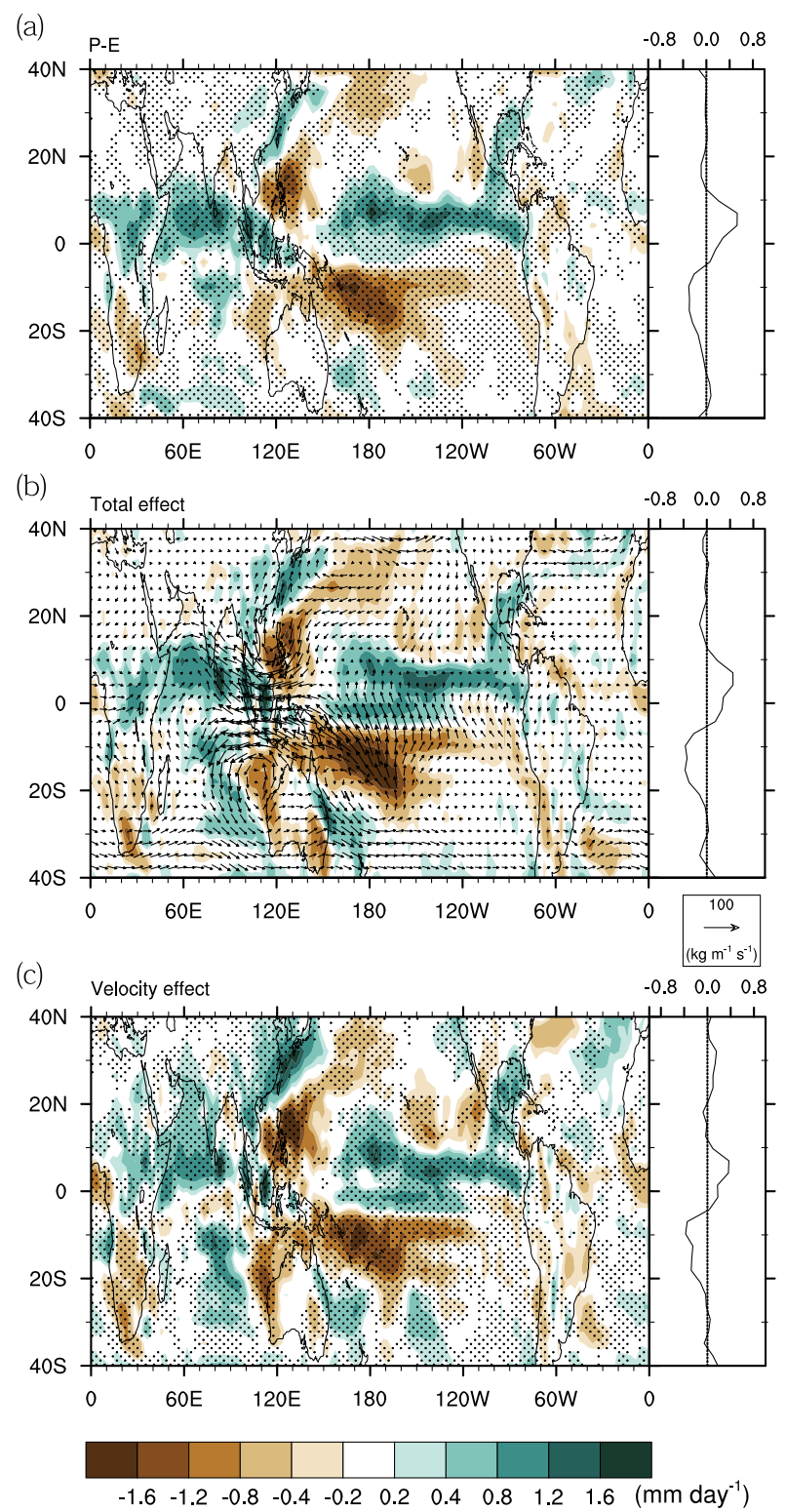

FIG. 4. Changes in the hydrological cycle for AO-R40 (OctoberJanuary, mm day $^{-1}$ ): (a) precipitation minus evaporation, (b) moisture flux convergence computed by monthly mean fields, and (c) moisture flux convergence due to monthly mean velocity change. In (b), the vertically integrated moisture flux vectors are also plotted. Zonal means are shown on the right. In (a) and (c), the grid points where the three ensemble members exhibit the same sign for the anomaly are stippled. See section 4a for details.

process is responsible for the maintenance of the peak SST warming, we conducted a CFRAM analysis (section $4 d$ ), which quantifies the relative contribution of different processes to the temperature change. The advantage of this method, compared to the surface energy balance analysis, is that the effect of the atmospheric temperature change on the surface temperature can be
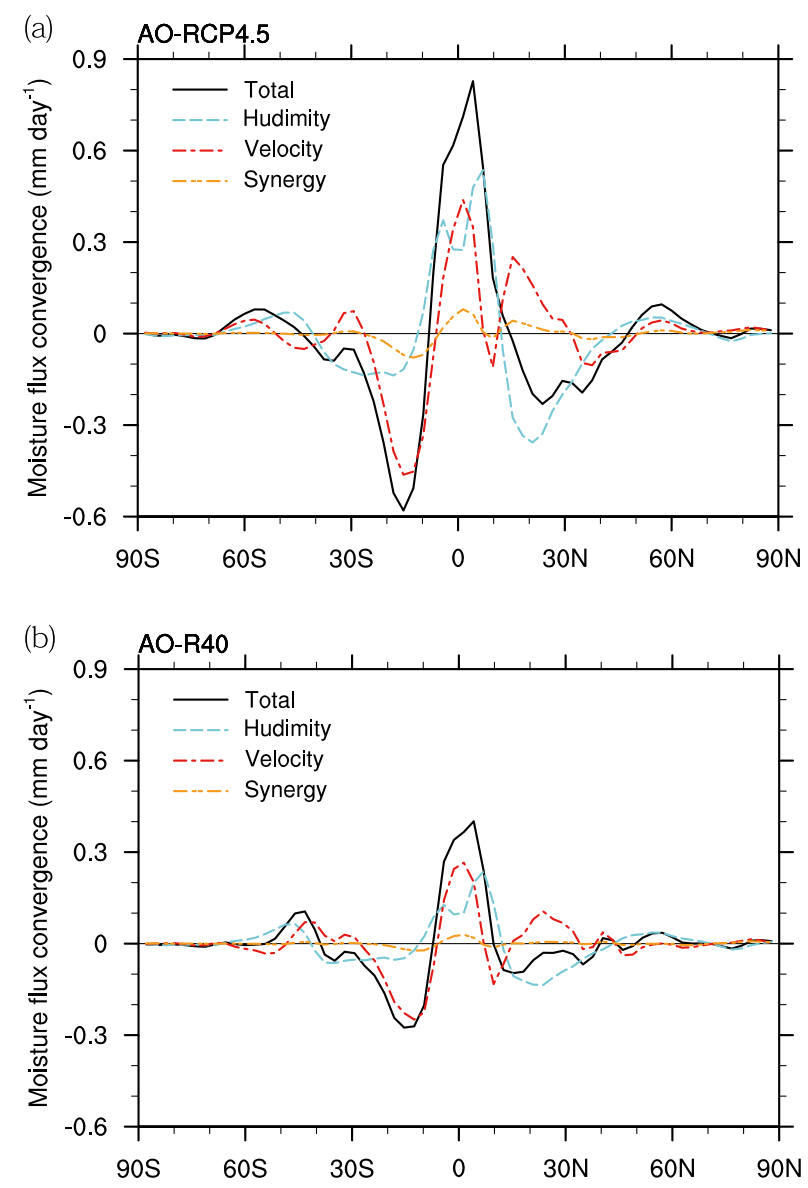

FIG. 5. Changes in the meridional convergence of moisture flux (October-January, mm day ${ }^{-1}$ ): (a) AO-RCP4.5 and (b) AO-R40. See section $4 b$ for details.

attributed to physical processes such as condensational heating and the atmospheric advection of heat. In Fig. 10, the black line represents the simulated SST change, and the red dashed line represents the sum of the individual CFRAM terms, indicating that the decomposition of the SST change into individual terms is useful. As expected, the water vapor feedback (WVP) contributes to the maintenance of the peak SST anomaly. This is, however, likely the result of positive feedback to the SST warming itself, rather than the cause. The RESS is related to the reduced ocean heat uptake. This RESS is not only affected by the SST warming but also by the vertical heat transport in the ocean. Indeed, the equatorial upwelling is the reason why the net heat flux to the ocean is positive in the eastern equatorial Pacific for the present-day ocean. Figures 11a and 11b show the meridional cross section of the tropical Pacific $\left(150^{\circ} \mathrm{E}-80^{\circ} \mathrm{W}\right)$ ocean temperature and upward velocity, respectively. The increase in the near-surface ocean temperature at the equator appears to be due to the 
(a)

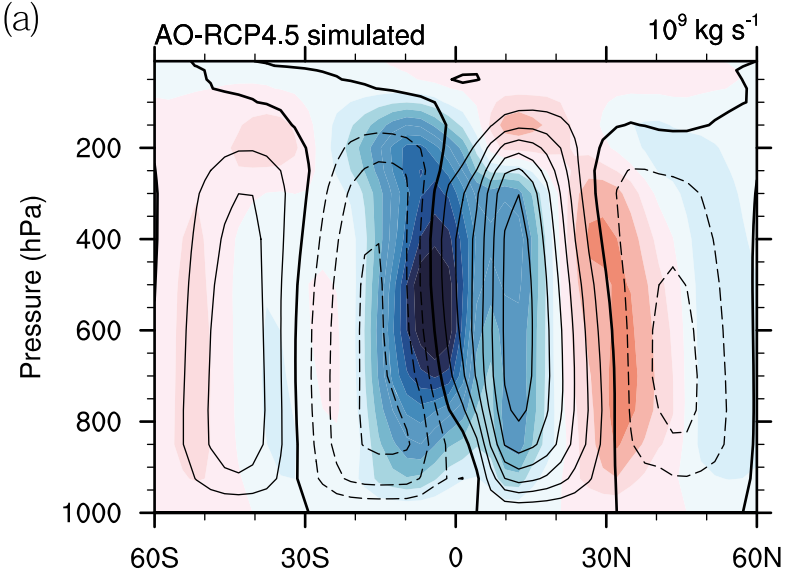

(b)

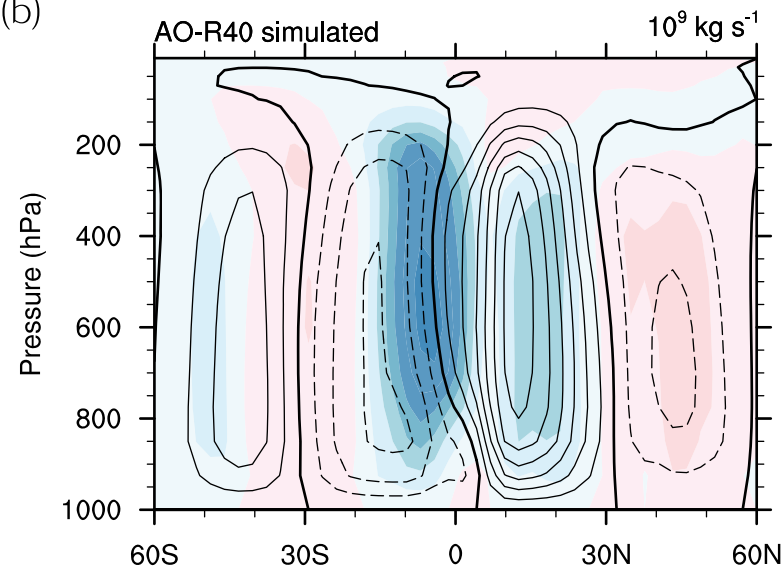

(c)

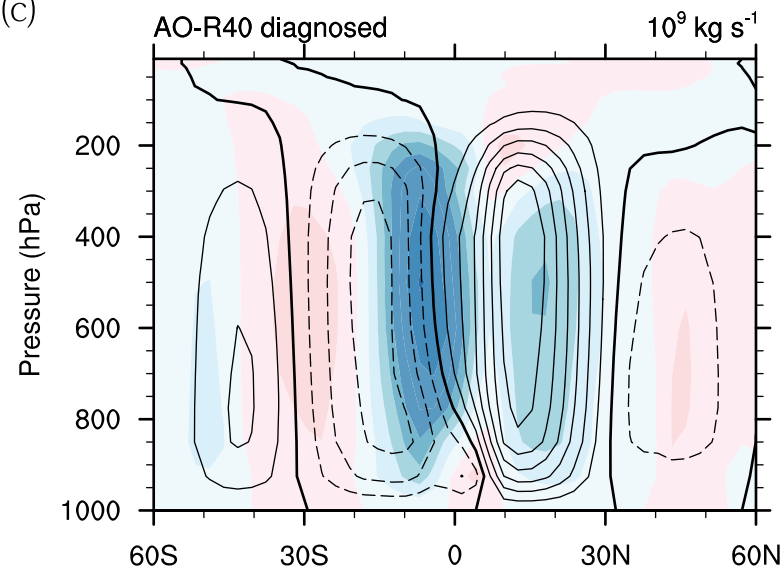

FIG. 6. Atmospheric meridional streamfunction (OctoberJanuary, $\times 10^{9} \mathrm{~kg} \mathrm{~s}^{-1}$ ): (a) AO-RCP4.5, (b) AO-R40, and (c) AO-R40 diagnosed by adding individual terms after solving the KuoEliassen equations. The line contours represent the late twentieth century, while the color shadings represent the change from the late twentieth century to the late twenty-first century. Positive values indicate clockwise circulation. The line contour intervals are $20 \times$ $10^{9} \mathrm{~kg} \mathrm{~s}^{-1}$, and negative values are indicated by dashed contours.

reduced upwelling of the colder water. The maximum SST anomaly in the eastern equatorial Pacific resembles the one shown by Tomas et al. (2016, their Fig. 5a). While Tomas et al. (2016) attributed the SST anomaly to the weakening of the subtropical ocean cells in both hemispheres in addition to the reduced upwelling and weakened stratification, the anomalous cell in our experiment exhibits a more cross-equatorial pattern (Fig. 11c), consistent with Green and Marshall (2017, their Fig. 6d).

The weakening of the surface trade winds at the equator and the anomalous easterly wind aloft indicates the concurrent weakening of the Walker circulation (Fig. 12). On the other hand, the peak SST warming at the equator is absent in AS-R40 without the ocean dynamical feedback (Fig. 9c). From the zonal gradient of the velocity potential, the weakening of the Walker circulation in AS-R40 is smaller than AO-R40. The Walker circulation change in AO-R40 is thus considered to be both the cause and effect of the reduced equatorial upwelling (through the Bjerknes feedback). Note that the anomalous warming minima in the subtropical southeastern Pacific present in AO-RCP4.5, AO-R40, and AS-R40 is largely due to the increased evaporation associated with the enhanced surface wind speeds.

\section{d. The role of ocean dynamics}

So far, it is unclear to what extent the upper ocean warming is attributable to atmospheric and oceanic drivers. First, we verified that nudging of the ocean temperature and salinity at only the top surface level (AO-RS40) is sufficient to reproduce the AO-R40 results. Second, we tested if the atmospheric pathways (AO-RW40) are sufficient to reproduce the AO$\mathrm{R} 40$ results. It is confirmed that a significant fraction of the extratropical warming influence on the tropical precipitation change in Fig. $3 \mathrm{~b}$ is reproduced using only the atmospheric pathways (Fig. S4; see also Table 2).

To verify that anomalous winds drive the lower Ekman convergence at the equator, and then raise the SST through the weakening of cold water upwelling, we applied the wind stress anomaly simulated by AO-R40 (Fig. 9b) and by AS-R40 (Fig. 9c) to the OGCM. As the surface air temperature is prescribed in the OGCM, anomalies in the simulated SST would be substantially suppressed. Therefore, the results cannot address the quantitative aspect of the proposed mechanism, but they can be used to test the qualitative nature of the mechanism. Figure 13 shows the SST response; anomalous wind stress in both sensitivity experiments results in the maximum SST warming near the Pacific equator, qualitatively confirming our hypothesis. 

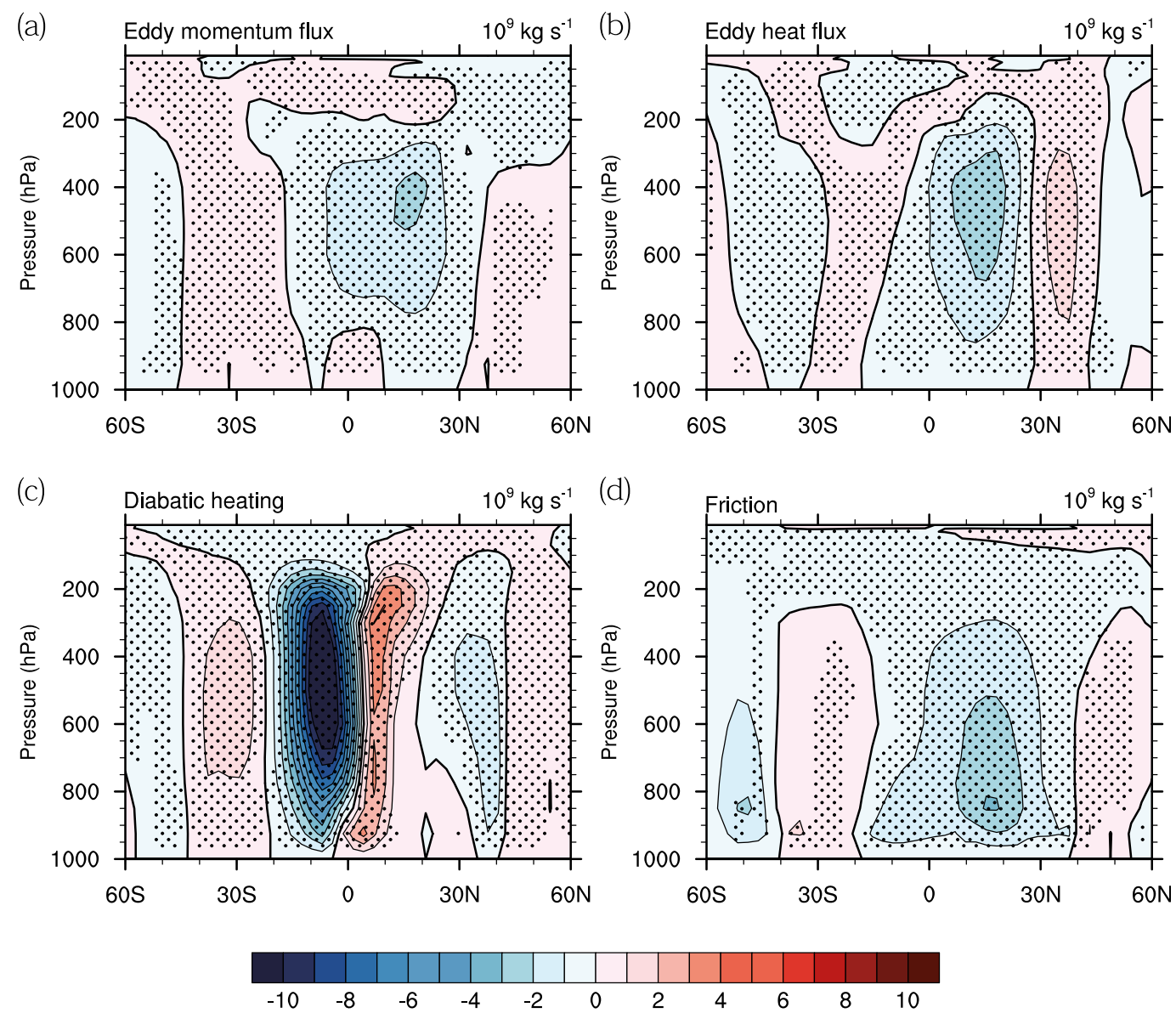

FIG. 7. Decomposition of the contributing terms to the change in the atmospheric meridional streamfunction for AO-R40 (October-January, $\times 10^{9} \mathrm{~kg} \mathrm{~s}^{-1}$ ): (a) eddy momentum flux term, (b) eddy heat flux term, (c) diabatic heating term, and (d) friction term. Positive values indicate clockwise circulation. The grid points where the three ensemble members exhibit the same sign for the anomaly are stippled. See section $4 \mathrm{c}$ for details.

Given that the diabatic heating anomaly with peak SST warming at the equator induces the clockwise Hadley circulation anomaly in the NH low latitudes (Fig. 7c), it is likely that the ocean dynamical feedback is negative in the northward displacement of tropical precipitation. Indeed, the equatorial peak SST warming is absent (Fig. 9c) and the increase in the precipitation occurs much farther north in AS-R40 without ocean dynamical feedback (Fig. 3d) compared to AO-R40 with ocean dynamical feedback (Fig. 3b). The centroid of the area-weighted precipitation between $20^{\circ} \mathrm{S}$ and $20^{\circ} \mathrm{N}$ moves northward by only $0.2^{\circ}$ in AO-R40, which is suppressed by a factor of 2, compared to $0.4^{\circ}$ in AS-R 40 . We note that Green and Marshall (2017) reported a factor of 4 decrease because of the ocean dynamical feedback. No meridional displacement of the tropical precipitation is seen in the difference between A-R40a and A-R40b when the tropical SST is fixed (not shown), indicating that the ocean thermal response is a necessary condition for the teleconnection of the mid-high-latitude warming to the tropical precipitation change.

\section{Discussion}

The impact of mid-high-latitude warming on the tropical precipitation change under future climate change projections was investigated with emphasis on the following two questions: 1) To what extent does the asymmetric extratropical warming between hemispheres explain the change in the distribution of tropical precipitation in the future? 2) What is the dynamical mechanism of the atmosphere and ocean for such a "teleconnection" if it exists? Earlier studies provided a simple yet robust theory for the influence of bipolar asymmetric warming on the meridional shift of tropical precipitation based on the interhemispheric AET change (Kang et al. 2009, 2008; Yoshimori and Broccoli 2008, 2009). This energy flux framework was obtained 

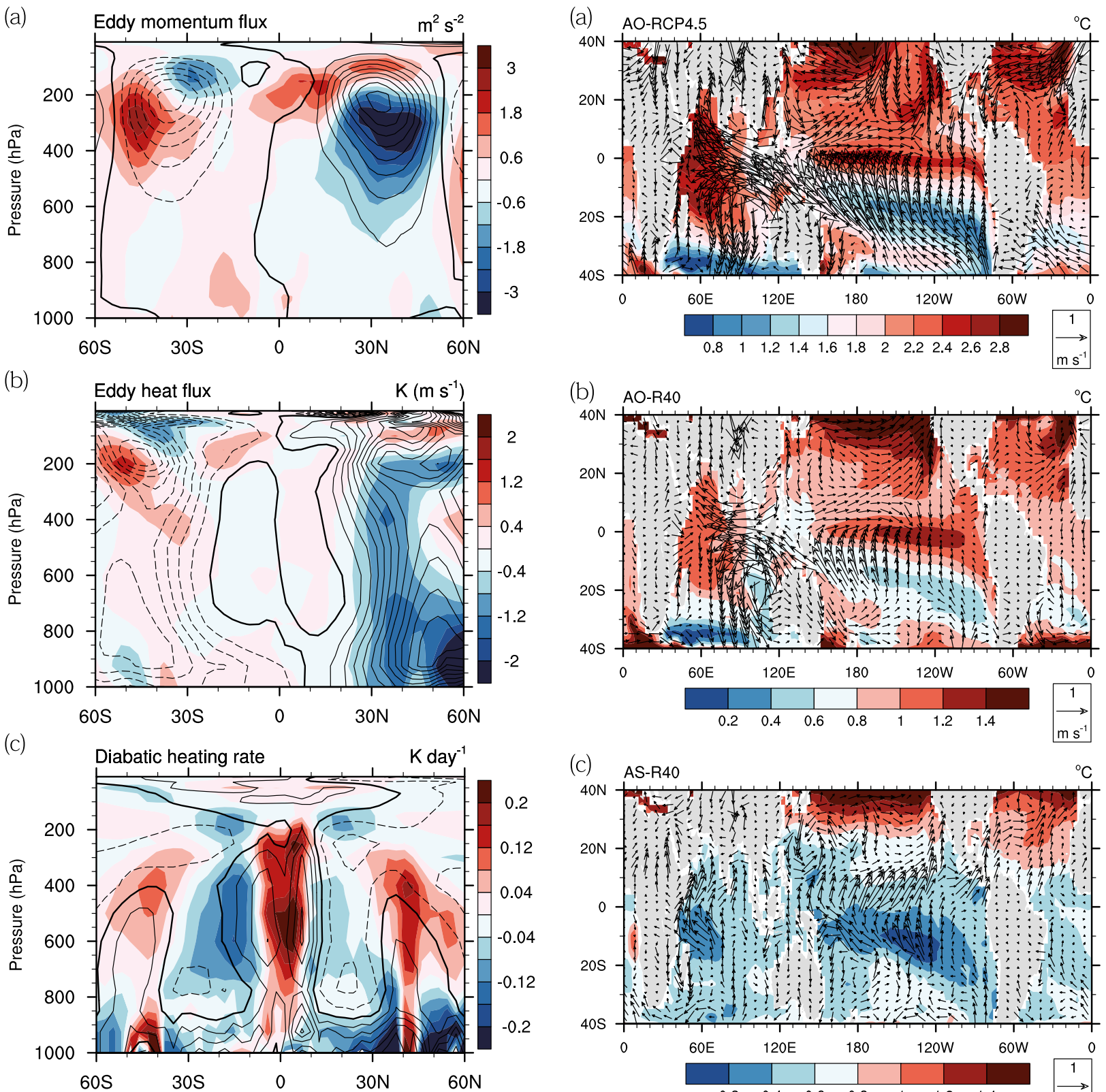

FIG. 8. Atmospheric changes for AO-R40 (October-January): (a) northward eddy momentum flux $\left(\mathrm{m}^{2} \mathrm{~s}^{-2}\right)$, line contour intervals $=10 \mathrm{~m}^{2} \mathrm{~s}^{-2}$; (b) northward eddy heat flux $\left(\mathrm{K} \mathrm{m} \mathrm{s}^{-1}\right)$, line contour intervals $=2 \mathrm{~K} \mathrm{~m} \mathrm{~s}^{-1}$; and (c) diabatic heating rate $\left(\mathrm{K} \mathrm{day}^{-1}\right)$, line contour intervals $=0.4 \mathrm{~K} \mathrm{day}^{-1}$. The contour lines represent the late twentieth century, while the color shadings represent the change from the late twentieth century to the late twenty-first century. Dashed contours indicate negative values.

using the thermodynamic ocean model component, and was challenged recently by Deser et al. (2015), who presented a striking difference in the precipitation response between AOGCM and AGCM with a slab ocean model [and more rigorously by Tomas et al. (2016)]. We note that the comparable (or larger) heat transport

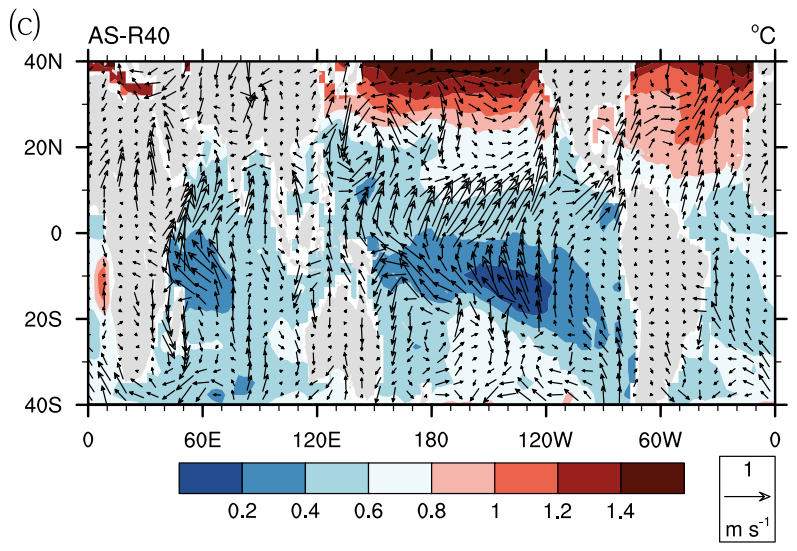

FIG. 9. Changes in sea surface temperature $\left({ }^{\circ} \mathrm{C}\right)$ and surface wind (October-January): (a) AO-RCP4.5, (b) AO-R40, and (c) AS$\mathrm{R} 40 \mathrm{~b}-\mathrm{AS}-\mathrm{R} 40 \mathrm{a}$. Note that the color scale in (a) is different from the others.

change in the ocean to that by the atmosphere was also reported by Ocko et al. (2014) in response to aerosol forcing. These results require some modification to the earlier framework. The idea proposed by Schneider et al. (2014) was recently demonstrated by Green and Marshall (2017) in idealized model experiments: the trade wind anomalies accompanying the anomalous Hadley circulation impose wind stress on the ocean. The 


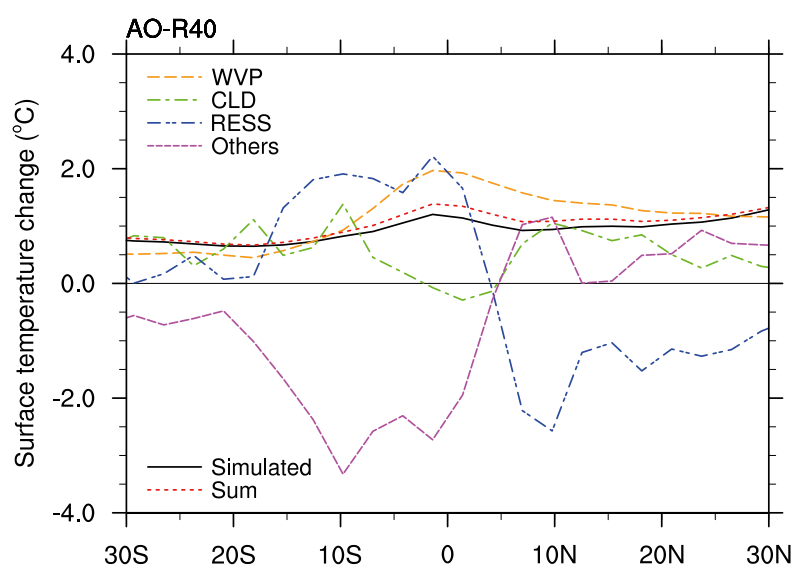

FIG. 10. Partial surface temperature changes in the Pacific $\left(150^{\circ} \mathrm{E}-80^{\circ} \mathrm{W}\right)$ for AO-R40 (October-January), diagnosed using the CFRAM technique $\left({ }^{\circ} \mathrm{C}\right)$. "WVP" is water vapor radiative feedback, "CLD" is cloud radiative feedback, "RESS" is net surface heat flux (heat storage and advection terms in the ocean), "Others" are all other terms, "Simulated" is simulated surface temperature change, and "Sum" is sum of all CFRAM terms. See section $4 \mathrm{~d}$ for details.

near-surface meridional flows of the atmosphere and ocean are both approximately Ekman balanced (between friction and Coriolis force): the flows are in opposite directions but with comparable magnitudes of mass transport. Figure $7 \mathrm{~d}$ indeed shows that the frictional drag induces anomalous meridional circulation. As there is a larger energy density contrast between the upper and lower branches in the oceanic cell than the atmospheric cell, more energy tends to be transported by the ocean. Our results are consistent with this modified energy framework of Green and Marshall (2017), in that the anomalous counterclockwise cross-equatorial ocean cell appears (Fig. 11c) and the OET change dominates over the AET change near the equator (Table 3). We note that the cross-equatorial AET change is about one-third of the OET change in AO$\mathrm{R} 40$ whereas it is about half in Green and Marshall (2017) and is almost zero in Deser et al. (2015).

Our results show a pronounced meridional displacement of the tropical precipitation compared to Deser et al. (2015). The difference between the results likely originates from the difference in model formulations, but the results might have been influenced by the choice of latitudes where the perturbation is applied. In Deser et al. (2015), the Arctic sea ice was effectively removed, while our study warmed the ocean at latitudes poleward of $40^{\circ}$ or $60^{\circ}$. Seo et al. (2014) reported, based on systematic forcing experiments with an AGCM without ocean dynamics, that the ITCZ shift has a similar sensitivity to the mid- and high-latitude perturbations. In their study, the magnitude of forcing was scaled to yield
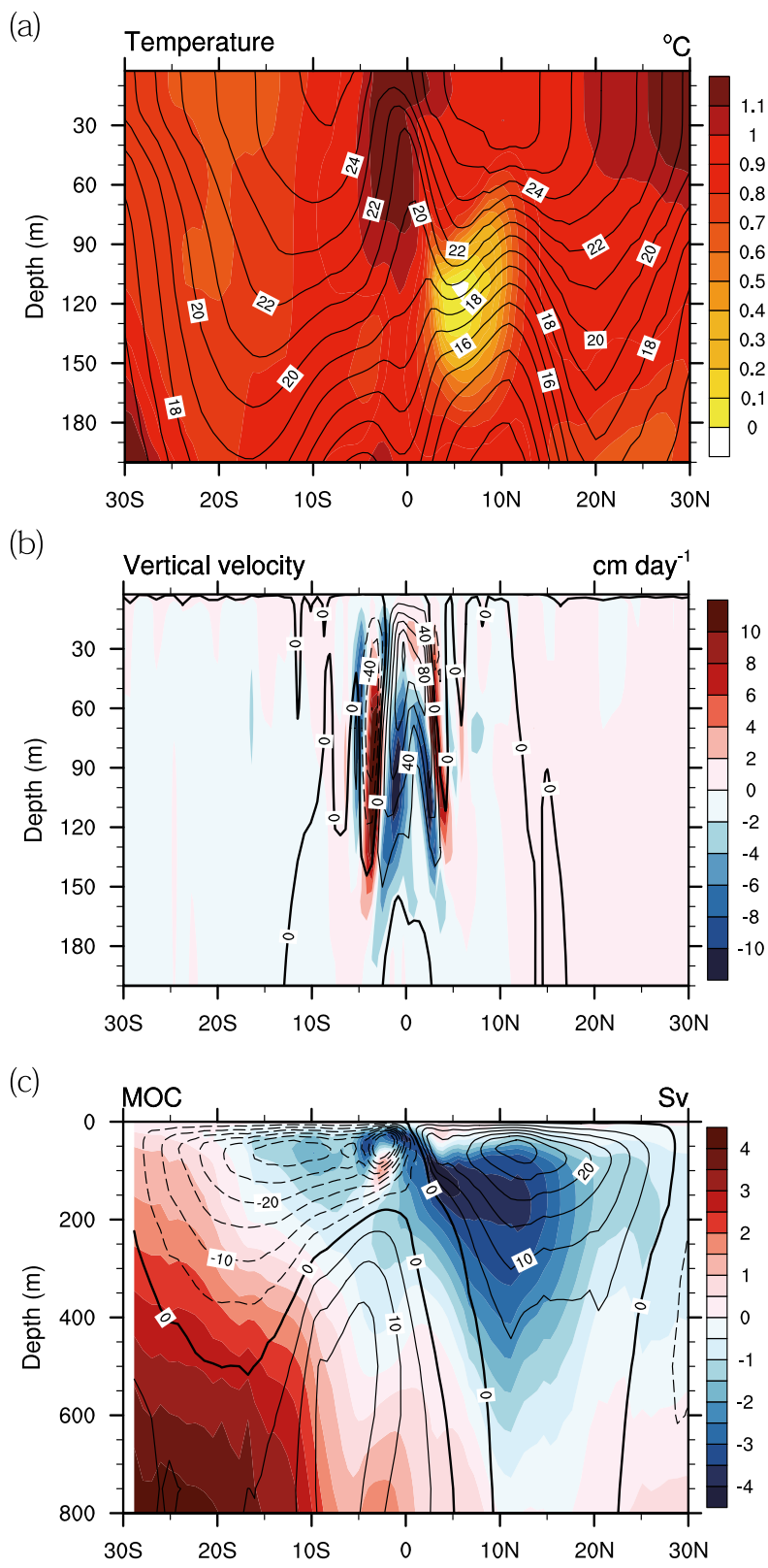

FIG. 11. Upper-ocean state for AO-R40 (October-January): (a) potential temperature in the Pacific $\left(150^{\circ} \mathrm{E}-80^{\circ} \mathrm{W}\right)\left({ }^{\circ} \mathrm{C}\right)$; and (b) vertical velocity in the Pacific $\left(150^{\circ} \mathrm{E}-80^{\circ} \mathrm{W}\right)\left(\mathrm{cm} \mathrm{day}^{-1}\right)$; and (c) meridional overturning streamfunction in the Pacific-Indian basin $(\mathrm{Sv})\left(1 \mathrm{~Sv} \equiv 10^{6} \mathrm{~m}^{3} \mathrm{~s}^{-1}\right)$. Positive values indicate clockwise circulation. The line contours represent the late twentieth century, while the color shadings represent the change from the late twentieth century to the late twenty-first century. Notice that the depth range in (c) is different from the others.

the same equivalent cross-equatorial OET anomaly. Without such scaling, the small area of perturbation in AO-R60 might be responsible for the much smaller response than AO-R40 in our case. The role of the reduced eddy activities proposed in our AO-R40 case, 

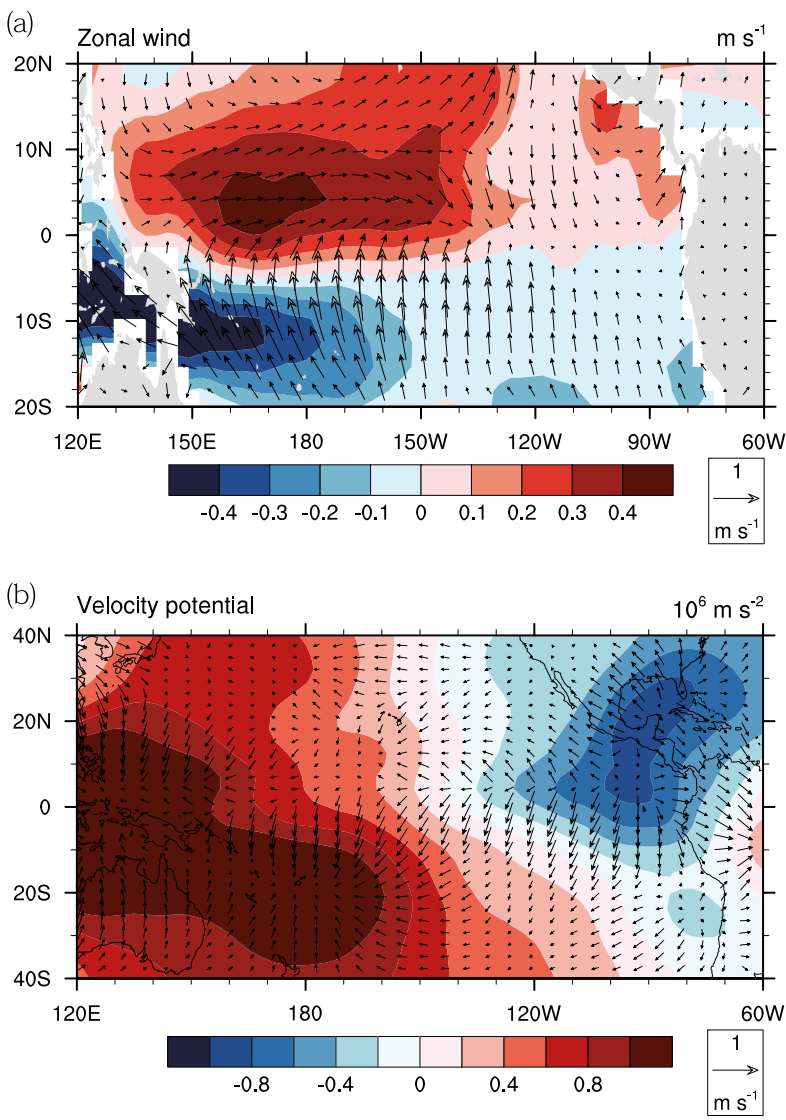

FIG. 12. Changes in the Walker circulation for AO-R40 (October-January): (a) zonal wind speed (shadings, $\mathrm{m} \mathrm{s}^{-1}$ ) and wind velocity (arrows) near the surface; and (b) velocity potential (shadings, $\times 10^{6} \mathrm{~m} \mathrm{~s}^{-2}$ ) and divergent wind velocity (arrows) at $200 \mathrm{hPa}$.

therefore, remains to be examined in a more general context. Yim et al. (2017) emphasized the possibility of a tropical influence on the Arctic warming amplification while trying to explain the statistical relation found between the meridional shift of tropical precipitation and Arctic warming amplification. In contrast, our results suggest the influence works in the opposite direction; that is, the Arctic (together with the midlatitudes) influences the tropics.

\section{Conclusions}

In the current study, we propose a dynamical framework to model the relation between extratropical warming and tropical precipitation change, as summarized in Fig. 14. This framework is consistent and complementary to the existing energy framework, although care must be exercised that the use of the nudging technique is equivalent to the adding of energy to high latitudes. The $\mathrm{NH}$ warms much more than the $\mathrm{SH}$ due to
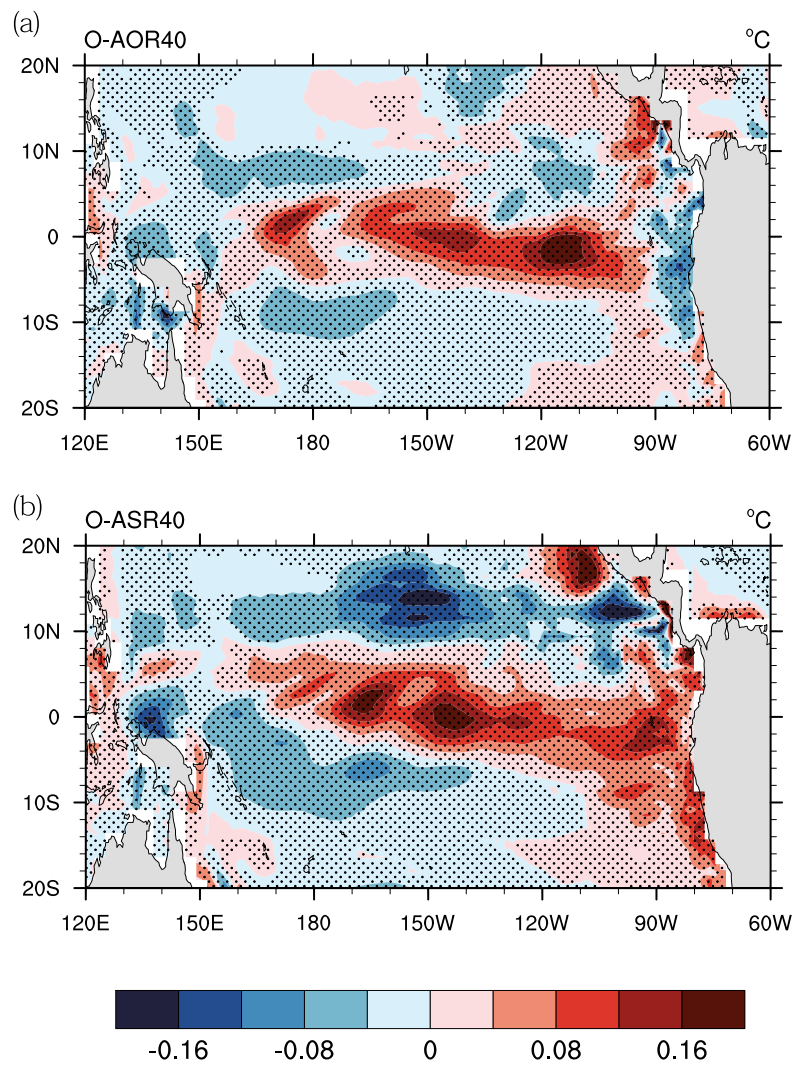

FIG. 13. Sea surface temperature response in the OGCM experiments to the wind stress change from the late twentieth century to the late twenty-first century: (a) wind stress anomaly from AOR40 and (b) wind stress anomaly from (AS-R40b - AS-R40a). The grid points where the difference is significant at the $5 \%$ level according to a $t$ test are stippled.

the difference in thermal inertia originating from the land-sea configuration and due to the Arctic warming amplification (Laîné et al. 2016; Yoshimori et al. 2017, 2014a, b). As a result, the meridional temperature gradient in the $\mathrm{NH}$ becomes lower and eddy activities weaken. To balance the reduced northward eddy heat and momentum transport, an anomalous counterclockwise Hadley circulation is required in the NH tropics.

TABLE 3. Energy transport change at the equator (PW) from the late twentieth century to the late twenty-first century (OctoberJanuary). The bottom row shows the difference between AS-R40b and AS-R40a.

\begin{tabular}{lccc}
\hline \multicolumn{1}{c}{ Expt } & Atmosphere & Ocean & Total \\
\hline AO-RCP4.5 & -0.11 & -0.40 & -0.51 \\
AO-R40 & -0.03 & -0.09 & -0.12 \\
AO-R60 & -0.02 & -0.09 & -0.11 \\
AO-RS40 & -0.06 & -0.16 & -0.22 \\
AO-RW40 & -0.04 & -0.18 & -0.22 \\
AS-R40b - AS-R40a & -0.10 & 0 & -0.10
\end{tabular}




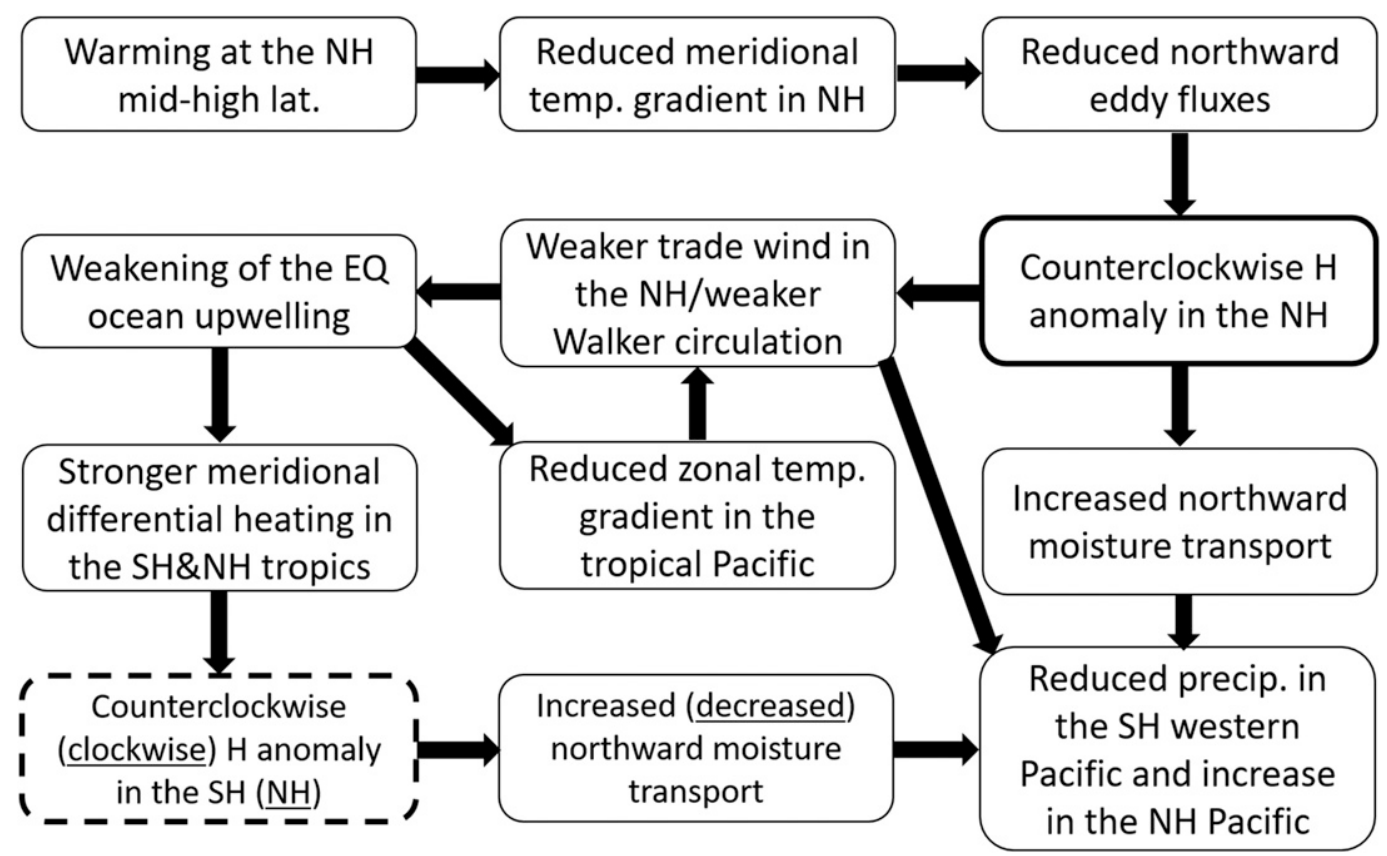

FIG. 14. Schematic diagram of the proposed mechanism ("NH" is Northern Hemisphere, "SH" is Southern Hemisphere, "H" is Hadley, "EQ" is equatorial, "lat." is latitude, and "temp." is temperature). In the Northern Hemisphere, the clockwise Hadley circulation anomaly induced by the ocean upwelling in the dashed-line box has a negative feedback to the counterclockwise Hadley circulation anomaly in the thick-line box.

The reduced eddy heat transport is consistent with the energy framework in that the AET decreases in the $\mathrm{NH}$ midlatitudes (Bischoff and Schneider 2014; Kang et al. 2009). The current dynamical framework also enables us to link the Hadley circulation response to the eddy momentum transport and the angular momentum constraint, required by Chiang and Friedman (2012) and Schneider et al. (2014) for a more complete theory. The anomalous NH cell weakens the trade winds, which reduces the cold water upwelling in the eastern equatorial Pacific. The maximum SST increase occurs in the equatorial Pacific, and generates a counterclockwise Hadley circulation anomaly in the SH tropics. The fact that the paired clockwise Hadley circulation anomaly in the $\mathrm{NH}$ tropics due to the differential heating counteracts the eddy-induced component is consistent with the energy framework: the northward migration of tropical precipitation is suppressed by the OET change, which creates the SST anomalies and the meridional differential heating in the atmosphere. Together with the net $\mathrm{NH}$ anomaly, the cross-equatorial counterclockwise Hadley cell transports moisture from the SH tropics to the $\mathrm{NH}$ tropics, causing a meridional displacement in the tropical precipitation. At the same time, the SST warming in the eastern equatorial Pacific weakens the Walker circulation through a decrease in the zonal SST gradient. The changes in the Hadley and Walker circulations result in reduced precipitation in the $\mathrm{SH}$ western Pacific (SPCZ) and increased precipitation in the NH tropics.

Our eddy flux argument to explain the connection between mid and low latitudes is based on the zonal mean analysis, and the development of a zonally asymmetric theory is desired. Furthermore, the model dependency in the response of the tropical precipitation to the extratropical warming asymmetry between the hemispheres needs to be investigated. Despite these remaining issues, we believe that the current study represents an important step forward by demonstrating the role of midlatitude atmospheric eddies and equatorial ocean upwelling. Here, the ocean dynamical feedback prevents the tropical precipitation from migrating farther north.

Acknowledgments. We are thankful to three anonymous reviewers for their useful suggestions, which helped us to improve the manuscript. This study benefitted from discussions with Mr. Yujin Hamano. We thank the MIROC development team for providing the model and Dr. Wing-Le Chan for technical advice. We also thank the developers of the freely available software NCL. All experiments were carried out using the JAMSTEC Earth Simulator 3 except for the OGCM experiments, which were conducted using the Fujitsu PRIMEHPC 
FX10 System at the ITC of the University of Tokyo. This research was supported by JSPS KAKENHI Grant $15 \mathrm{~K} 05280$.

\section{REFERENCES}

Adam, O., T. Bischoff, and T. Schneider, 2016a: Seasonal and interannual variations of the energy flux equator and ITCZ. Part I: Zonally averaged ITCZ position. J. Climate, 29, 3219-3230, https://doi.org/10.1175/JCLI-D-15-0512.1.

,-- , and,$- 2016 \mathrm{~b}$ : Seasonal and interannual variations of the energy flux equator and ITCZ. Part II: Zonally varying shifts of the ITCZ. J. Climate, 29, 7281-7293, https://doi.org/ 10.1175/JCLI-D-15-0710.1.

Allen, R. J., A. T. Evan, and B. B. B. Booth, 2015: Interhemispheric aerosol radiative forcing and tropical precipitation shifts during the late twentieth century. J. Climate, 28, 8219-8246, https://doi.org/10.1175/JCLI-D-15-0148.1.

Bakker, P., and Coauthors, 2016: Fate of the Atlantic Meridional Overturning Circulation: Strong decline under continued warming and Greenland melting. Geophys. Res. Lett., 43, 12 252-12 260, https://doi.org/10.1002/2016GL070457.

Bischoff, T., and T. Schneider, 2014: Energetic constraints on the position of the intertropical convergence zone. J. Climate, 27, 4937-4951, https://doi.org/10.1175/JCLI-D-13-00650.1.

Broccoli, A. J., K. A. Dahl, and R. J. Stouffer, 2006: Response of the ITCZ to Northern Hemisphere cooling. Geophys. Res. Lett., 33, L01702, https://doi.org/10.1029/2005GL024546.

Chiang, J. C. H., and A. R. Friedman, 2012: Extratropical cooling, interhemispheric thermal gradients, and tropical climate change. Annu. Rev. Earth Planet. Sci., 40, 383-412, https:// doi.org/10.1146/annurev-earth-042711-105545.

Cvijanovic, I., and J. C. H. Chiang, 2013: Global energy budget changes to high latitude North Atlantic cooling and the tropical ITCZ response. Climate Dyn., 40, 1435-1452, https:// doi.org/10.1007/s00382-012-1482-1.

Deser, C., R. Tomas, M. Alexander, and D. Lawrence, 2010: The seasonal atmospheric response to projected Arctic sea ice loss in the late twenty-first century. J. Climate, 23, 333-351, https:// doi.org/10.1175/2009JCLI3053.1.

_, _ and L. T. Sun, 2015: The role of ocean-atmosphere coupling in the zonal-mean atmospheric response to Arctic sea ice loss. J. Climate, 28, 2168-2186, https://doi.org/10.1175/ JCLI-D-14-00325.1.

— L. Lun, R. A. Tomas, and J. Screen, 2016: Does ocean coupling matter for the northern extratropical response to projected Arctic sea ice loss? Geophys. Res. Lett., 43, 2149-2157, https://doi.org/10.1002/2016GL067792.

Donohoe, A., J. Marshall, D. Ferreira, and D. McGee, 2013: The relationship between ITCZ location and cross-equatorial atmospheric heat transport: From the seasonal cycle to the Last Glacial Maximum. J. Climate, 26, 3597-3618, https://doi.org/ 10.1175/JCLI-D-12-00467.1.

,,,--- K. Armour, and D. McGee, 2014: The interannual variability of tropical precipitation and interhemispheric energy transport. J. Climate, 27, 3377-3392, https://doi.org/ 10.1175/JCLI-D-13-00499.1.

Friedman, A. R., Y. T. Hwang, J. C. H. Chiang, and D. M. W. Frierson, 2013: Interhemispheric temperature asymmetry over the twentieth century and in future projections. J. Climate, $\mathbf{2 6}$ 5419-5433, https://doi.org/10.1175/JCLI-D-12-00525.1.

Frierson, D. M. W., and Y.-T. Hwang, 2012: Extratropical influence on ITCZ shifts in slab ocean simulations of global warming.
J. Climate, 25, 720-733, https://doi.org/10.1175/JCLI-D-1100116.1.

, and Coauthors, 2013: Contribution of ocean overturning circulation to tropical rainfall peak in the Northern Hemisphere. Nat. Geosci., 6, 940-944, https://doi.org/10.1038/ ngeo1987.

Fuckar, N. S., S. P. Xie, R. Farneti, E. A. Maroon, and D. M. W. Frierson, 2013: Influence of the extratropical ocean circulation on the intertropical convergence zone in an idealized coupled general circulation model. J. Climate, 26, 4612-4629, https:// doi.org/10.1175/JCLI-D-12-00294.1.

Green, B., and J. Marshall, 2017: Coupling of trade winds with ocean circulation damps ITCZ shifts. J. Climate, 30, 43954411, https://doi.org/10.1175/JCLI-D-16-0818.1.

Grotjahn, R., 1993: Global Atmospheric Circulations: Observations and Theories. Oxford University Press, $450 \mathrm{pp}$.

Hasumi, H., and S. Emori, Eds., 2004: K-1 coupled GCM (MIROC) description. The University of Tokyo Center for Climate System Research Tech. Rep., 38 pp., http:// ccsr.aori.u-tokyo.ac.jp/ hasumi/miroc_description.pdf.

Hawcroft, M., J. M. Haywood, M. Collins, A. Jones, A. C. Jones, and G. Stephens, 2017: Southern Ocean albedo, interhemispheric energy transports and the double ITCZ: Global impacts of biases in a coupled model. Climate Dyn., 48, 22792295, https://doi.org/10.1007/s00382-016-3205-5.

Hill, S. A., Y. Ming, and I. M. Held, 2015: Mechanisms of forced tropical meridional energy flux change. J. Climate, 28, 17251742, https://doi.org/10.1175/JCLI-D-14-00165.1.

Holton, J. R., and G. J. Hakim, 2013: An Introduction to Dynamic Meteorology. Academic Press, 552 pp.

Hwang, Y. T., and D. M. W. Frierson, 2013: Link between the double-Intertropical Convergence Zone problem and cloud biases over the Southern Ocean. Proc. Natl. Acad. Sci. USA, 110, 4935-4940, https://doi.org/10.1073/pnas.1213302110.

, - _ , and S. M. Kang, 2013: Anthropogenic sulfate aerosol and the southward shift of tropical precipitation in the late 20th century. Geophys. Res. Lett., 40, 2845-2850, https:// doi.org/10.1002/grl.50502.

Kang, S. M., I. M. Held, D. M. W. Frierson, and M. Zhao, 2008: The response of the ITCZ to extratropical thermal forcing: Idealized slab-ocean experiments with a GCM. J. Climate, 21, 35213532, https://doi.org/10.1175/2007JCLI2146.1.

—, D. M. W. Frierson, and I. M. Held, 2009: The tropical response to extratropical thermal forcing in an idealized GCM: The importance of radiative feedbacks and convective parameterization. J. Atmos. Sci., 66, 2812-2827, https://doi.org/ 10.1175/2009JAS2924.1.

Kay, J. E., C. Wall, V. Yettella, B. Medeiros, C. Hannay, P. Caldwell, and C. Bitz, 2016: Global climate impacts of fixing the Southern Ocean shortwave radiation bias in the Community Earth System Model (CESM). J. Climate, 29, 4617-4636, https://doi.org/10.1175/JCLI-D-15-0358.1.

Keith, D. W., 1995: Meridional energy transport: Uncertainty in zonal means. Tellus, 47A, 30-44, https://doi.org/10.3402/ tellusa.v47i1.11492.

Krishnamurti, T. N., L. Stefanova, and V. Misra, 2013: Tropical Meteorology: An Introduction. Springer, 424 pp.

Laîné, A., M. Yoshimori, and A. Abe-Ouchi, 2016: Surface Arctic amplification factors in CMIP5 models: Land and oceanic surfaces and seasonality. J. Climate, 29, 3297-3316, https:// doi.org/10.1175/JCLI-D-15-0497.1.

Lu, J. H., and M. Cai, 2009: A new framework for isolating individual feedback processes in coupled general circulation 
climate models. Part I: Formulation. Climate Dyn., 32, 873885, https://doi.org/10.1007/s00382-008-0425-3.

Marshall, J., A. Donohoe, D. Ferreira, and D. McGee, 2014: The ocean's role in setting the mean position of the Inter-Tropical Convergence Zone. Climate Dyn., 42, 1967-1979, https:// doi.org/10.1007/s00382-013-1767-z.

McGee, D., A. Donohoe, J. Marshall, and D. Ferreira, 2014: Changes in ITCZ location and cross-equatorial heat transport at the Last Glacial Maximum, Heinrich Stadial 1, and the midHolocene. Earth Planet. Sci. Lett., 390, 69-79, https://doi.org/ 10.1016/j.epsl.2013.12.043.

Meehl, G. A., C. Covey, K. E. Taylor, T. Delworth, R. J. Stouffer, M. Latif, B. McAvaney, and J. F. Mitchell, 2007: The WCRP CMIP3 multimodel dataset: A new era in climate change research. Bull. Amer. Meteor. Soc., 88, 1383-1394, https://doi.org/ 10.1175/BAMS-88-9-1383.

Ocko, I. B., V. Ramaswamy, and Y. Ming, 2014: Contrasting climate responses to the scattering and absorbing features of anthropogenic aerosol forcings. J. Climate, 27, 5329-5345, https://doi.org/10.1175/JCLI-D-13-00401.1.

Oka, A., H. Hasumi, and A. Abe-Ouchi, 2012: The thermal threshold of the Atlantic meridional overturning circulation and its control by wind stress forcing during glacial climate. Geophys. Res. Lett., 39, L09709, https://doi.org/10.1029/ 2012GL051421.

Press, W. H., B. P. Flannery, S. A. Teukolsky, and W. T. Vetterling, 1992: Numerical Recipes in Fortran 77: The Art of Scientific Computing. 2nd ed. Cambridge University Press, 933 pp.

Rotstayn, L. D., and U. Lohmann, 2002: Tropical rainfall trends and the indirect aerosol effect. J. Climate, 15, 2103-2116, https://doi.org/10.1175/1520-0442(2002)015<2103: TRTATI $>2.0 . \mathrm{CO} ; 2$.

Schneider, T., T. Bischoff, and G. H. Haug, 2014: Migrations and dynamics of the intertropical convergence zone. Nature, 513, 45-53, https://doi.org/10.1038/nature13636.

Seo, J., S. M. Kang, and D. M. W. Frierson, 2014: Sensitivity of intertropical convergence zone movement to the latitudinal position of thermal forcing. J. Climate, 27, 3035-3042, https:// doi.org/10.1175/JCLI-D-13-00691.1.
Tatebe, H., Y. Imada, M. Mori, M. Kimoto, and H. Hasumi, 2013: Control of decadal and bidecadal climate variability in the tropical Pacific by the off-equatorial South Pacific Ocean. J. Climate, 26, 6524-6534, https://doi.org/10.1175/JCLI-D-12-00137.1.

Taylor, K. E., R. J. Stouffer, and G. A. Meehl, 2012: An overview of CMIP5 and the experiment design. Bull. Amer. Meteor. Soc., 93, 485-498, https://doi.org/10.1175/BAMS-D-11-00094.1.

Tomas, R. A., C. Deser, and L. T. Sun, 2016: The role of ocean heat transport in the global climate response to projected Arctic sea ice loss. J. Climate, 29, 6841-6859, https://doi.org/10.1175/ JCLI-D-15-0651.1.

Yim, B. Y., S.-W. Yeh, and J.-S. Kug, 2017: Inter-model diversity of Arctic amplification caused by global warming and its relationship with the Inter-tropical Convergence Zone in CMIP5 climate models. Climate Dyn., 48, 3799-3811, https:// doi.org/10.1007/s00382-016-3303-4.

Yoshimori, M., and A. J. Broccoli, 2008: Equilibrium response of an atmosphere-mixed layer ocean model to different radiative forcing agents: Global and zonal mean response. J. Climate, 21, 4399-4423, https://doi.org/10.1175/2008JCLI2172.1. , and - 2009: On the link between Hadley circulation changes and radiative feedback processes. Geophys. Res. Lett., 36, L20703, https://doi.org/10.1029/2009GL040488.

— C. C. Raible, T. F. Stocker, and M. Renold, 2006: On the interpretation of low-latitude hydrological proxy records based on Maunder Minimum AOGCM simulations. Climate Dyn., 27, 493-513, https://doi.org/10.1007/s00382-006-0144-6.

_- A. Abe-Ouchi, M. Watanabe, A. Oka, and T. Ogura, 2014a: Robust seasonality of Arctic warming processes in two different versions of the MIROC GCM. J. Climate, 27, 63586375, https://doi.org/10.1175/JCLI-D-14-00086.1.

- M. Watanabe, A. Abe-Ouchi, H. Shiogama, and T. Ogura, 2014b: Relative contribution of feedback processes to Arctic amplification of temperature change in MIROC GCM. Climate Dyn., 42, 1613-1630, https://doi.org/10.1007/s00382-013-1875-9.

—, A. Abe-Ouchi, and A. Lainé, 2017: The role of atmospheric heat transport and regional feedbacks in the Arctic warming at equilibrium. Climate Dyn., 49, 3457-3472, https://doi.org/ 10.1007/s00382-017-3523-2. 